OPEN ACCESS

Edited by:

James A. Ankrum,

The University of lowa, United States

Reviewed by:

Olle Thor,

Karolinska Institutet (KI), Sweden

Karen English,

Maynooth University, Ireland

*Correspondence:

Céline Grégoire

celine.gregoire@chuliege.be

tThese authors share co-senior authorship

Specialty section

This article was submitted to Alloimmunity and Transplantation, a section of the journal

Frontiers in Immunology

Received: 14 January 2019

Accepted: 08 March 2019

Published: 02 April 2019

Citation:

Grégoire C, Ritacco C, Hannon M Seidel L, Delens L, Belle L, Dubois S,

Vériter $S$, Lechanteur $C$, Briquet $A$,

Servais S, Ehx G, Beguin Y and

Baron F (2019) Comparison of

Mesenchymal Stromal Cells From

Different Origins for the Treatment of

Graft-vs.-Host-Disease in a

Humanized Mouse Model.

Front. Immunol. 10:619.

doi: 10.3389/fimmu.2019.00619

\section{Comparison of Mesenchymal Stromal Cells From Different Origins for the Treatment of Graft-vs.-Host-Disease in a Humanized Mouse Model}

Céline Grégoire ${ }^{1,2 *}$, Caroline Ritacco ${ }^{1}$, Muriel Hannon ${ }^{1}$, Laurence Seidel ${ }^{3}$, Loïc Delens ${ }^{1}$, Ludovic Belle ${ }^{1}$, Sophie Dubois ${ }^{1}$, Sophie Vériter ${ }^{4}$, Chantal Lechanteur ${ }^{5}$, Alexandra Briquet ${ }^{5}$, Sophie Servais ${ }^{1,2}$, Gregory Ehx ${ }^{1}$, Yves Beguin ${ }^{1,2,5 t}$ and Frédéric Baron ${ }^{1,2+}$

${ }^{1}$ Hematology Research Unit, GIGA-I3, GIGA Institute, University of Liège, Liège, Belgium, ${ }^{2}$ Department of Clinical Hematology, University Hospital Center of Liège, Liège, Belgium, ${ }^{3}$ Department of Biostatistics, SIMÉ, University Hospital Center of Liège, Liège, Belgium, ${ }^{4}$ Endocrine Cell Therapy, Centre of Tissue and Cellular Therapy, Cliniques Universitaires Saint-Luc, Brussels, Belgium, ${ }^{5}$ Laboratory of Cell and Gene Therapy, University Hospital Center and University of Liège, Liège, Belgium

Mesenchymal stromal cells (MSCs) have potent immunomodulatory properties that make them an attractive tool against graft- vs.-host disease (GVHD). However, despite promising results in phase I/II studies, bone marrow (BM-) derived MSCs failed to demonstrate their superiority over placebo in the sole phase III trial reported thus far. MSCs from different tissue origins display different characteristics, but their therapeutic benefits have never been directly compared in GVHD. Here, we compared the impact of BM-, umbilical cord (UC-), and adipose-tissue (AT-) derived MSCs on T-cell function in vitro and assessed their efficacy for the treatment of GVHD induced by injection of human peripheral blood mononuclear cells in NOD-scid IL-2R $\gamma^{\text {null }} H L A-A 2 / H H D$ mice. In vitro, resting BM- and AT-MSCs were more potent than UC-MSCs to inhibit lymphocyte proliferation, whereas UC- and AT-MSCs induced a higher regulatory T-cell $\left(C D 4^{+} \mathrm{CD} 25^{+} \mathrm{FoxP}^{+}\right) / \mathrm{T}$ helper 17 ratio. Interestingly, AT-MSCs and UC-MSCs activated the coagulation pathway at a higher level than BM-MSCs. In vivo, AT-MSC infusions were complicated by sudden death in 4 of 16 animals, precluding an analysis of their efficacy. Intravenous MSC infusions (UC- or BM- combined) failed to significantly increase overall survival (OS) in an analysis combining data from 80 mice (hazard ratio $[\mathrm{HR}]=0.59$, $95 \%$ confidence interval $[\mathrm{Cl}] 0.32-1.08, P=0.087$ ). In a sensitivity analysis we also compared OS in control vs. each MSC group separately. The results for the BM-MSC vs. control comparison was $\mathrm{HR}=0.63(95 \% \mathrm{Cl} 0.30-1.34, P=0.24)$ while the figures for the UC-MSC vs. control comparison was $\mathrm{HR}=0.56(95 \% \mathrm{Cl} 0.28-1.10, P=0.09)$. 
Altogether, these results suggest that MSCs from various origins have different effects on immune cells in vitro and in vivo. However, none significantly prevented death from GVHD. Finally, our data suggest that the safety profile of AT-MSC and UC-MSC need to be closely monitored given their pro-coagulant activities in vitro.

Keywords: mesenchymal stromal cells, graft-vs.-host-disease, hematopoietic stem cell transplantation, xenogeneic, NSG, bone marrow, umbilical cord, adipose tissue

\section{INTRODUCTION}

Allogeneic hematopoietic cell transplantation (allo-HCT) has remained the best therapeutic option for many patients with hematological or immune disorders (1). Its efficacy in hematological malignancies depends not only on the chemo/radiotherapy given in the conditioning regimen, but also on graft-vs.-tumor (GvT) effects mediated mainly through donor $\mathrm{T}$ cells contained in the graft $(2,3)$. However, donor $\mathrm{T}$ cells can also recognize the tissues of the recipient as foreign, causing graft-vs.-host disease (GVHD) (4-6), a life-threatening complication of allo-HCT $(7,8)$. The complex physiopathology of acute GVHD involves both innate and adaptive immune activation in response to inflammatory triggers such as damageassociated molecular pattern (DAMP) molecules released from damaged cells or extracellular matrix, and pathogen-associated molecular pattern (PAMP) molecules from bacteria, viruses and fungi. The main effectors of acute GVHD are donor $\mathrm{CD}^{+}$ and $\mathrm{CD}^{+} \mathrm{T}$ cells, the latest causing tissue damages through expression of FAS ligand and release of granzyme B, perforin and cytokines such as tumor necrosis factor-alpha (TNF $\alpha)$. CD4 ${ }^{+} \mathrm{T}$ cell activation, differentiation, and survival require three signals: (1) interaction of T-cell receptor (TCR) with antigen presenting cells (APCs) expressing host major histocompatibility complex (MHC) and/or host minor histocompatibility antigens, (2) positive costimulatory signals (including CD28, ICOS, CD40L, OX40, 4-1BB) and (3) cytokines such as interleukin (IL)-2, IL-7, IL-15, and polarizing T helper 1 (Th1), Th2 and Th17 cytokines (9). Regulatory mechanisms include mainly regulatory T cells (Tregs; $\mathrm{CD}^{+}{ }^{+} \mathrm{CD} 25^{+} \mathrm{FoxP}^{+}$), but also type 1 regulatory $\mathrm{T}$ cells (Tr1) secreting IL-10, myeloid-derived suppressor cells and tolerogenic dendritic cells (9).

GVHD has remained a serious limitation of allo-HCT $(7,8)$. Only half of the patients respond to first-line steroid therapy, and the outcome of patients with steroid-refractory GVHD has remained dismal (10). Therefore, there is a real need for new effective strategies to treat acute GVHD.

Mesenchymal stromal cells (MSCs) are multipotent progenitors within the bone marrow capable of differentiating into various cells and tissues, such as chondrocytes, osteoblasts and adipocytes (11). In addition to their support to hematopoiesis, MSCs have demonstrated potent tissue repair abilities and immunomodulatory properties (12, 13). Specifically, MSCs interact with lymphocytes, natural killer (NK) cells and APCs, through release of soluble factors [such as prostaglandin-E2, transforming growth factor beta-1, or human leukocyte antigen [HLA]-G but also, as recently reported, programmed death-ligand [PD-L] 1 and PD-L2 (14)], induction of indoleamine 2,3 dioxygenase (IDO), and/or cell contact signaling $(12,13)$. Importantly, MSCs have similar immunosuppressive potency against autologous and allogeneic lymphocytes. All these characteristics make them a promising tool against GVHD (15-17).

In the last 2 decades, MSC infusions have been evaluated for both prevention and treatment of GVHD. A number of phase II trials reported lower incidences of acute GVHD in patients cotransplanted with MSCs than in historical or concurrent controls (18-20). However, a meta-analysis of trials of MSC infusion in the setting of GVHD prophylaxis failed to demonstrate a significant impact of MSC infusion on GVHD (21). Among the phase I/II trials assessing the efficacy of allogeneic MSCs for the treatment of steroid refractory acute GVHD, complete response (CR) rates varied between 10 and 75\% (22-24), providing a median 6-month survival of 63\% (95\% CI 50-74\%) after MSC infusion in another large meta-analysis (25). Importantly, the sole randomized placebo-controlled phase III trial assessing MSC infusions as treatment for steroid-refractory GVHD reported thus far failed to reach the primary endpoint (increase in the rates of durable $[\geq 28$ days] CR) (26). The heterogeneity in the design of these studies as well as the heterogeneity in MSC products used might have participated in the discrepancies between their results. Based on these observations, a recent trial aimed at selecting subjects likely to be responders, in light of the results of the first clinical studies. Early MSC therapy in pediatric gut and/or liver steroid-refractory GVHD seems indeed promising with improvement of overall response at day 28 (CR + partial response [PR]: 69\%) (27), although the final results of the trial have not been published yet. MSCs can also display pro-inflammatory properties (including secretion of proinflammatory cytokines such as IL-6 and IL-8) that may hamper their efficacy (28). These findings stress the need for more preclinical studies aiming to a more thorough understanding of MSC mechanisms of action and parameters of efficacy.

Since their first discovery in bone marrow (BM), MSCs have been successfully isolated from several other tissues, including adipose tissue (AT), umbilical cord (UC), umbilical cord blood, and placenta. MSCs from different sources share many characteristics, but also display many phenotypical and functional differences $(29,30)$. Although they all exhibit immunomodulatory properties, few studies directly compared their therapeutic benefits. Here, we compared the ability of BMMSCs, AT-MSCs, and UC-MSCs to treat GVHD in NOD-scid IL-2R $\gamma^{\text {null }}$ HLA-A2/HHD (NSG-HLA-A2/HHD) mice infused with human peripheral blood mononuclear cells (PBMCs) from 
non-HLA-A2 donors. We recently demonstrated that GVHD in that humanized model is caused by a limited number of CD4 and CD8 xeno- as well as probably allo- reactive T-cell clones that expand via activation of the TCR, costimulation, IL-2/STAT5, mTOR, and Aurora kinase A pathways and differentiate into effector cells in GVHD-target organs, secreting high amounts of interferon gamma (IFN $\gamma$ ) and $\mathrm{TNF} \alpha$ (31). This model mimics some important aspects of GVHD pathogenesis in humans and non-human primates (32).

\section{MATERIALS AND METHODS}

\section{Mesenchymal Stromal Cells}

BM-MSCs were produced at the Laboratory of Cellular and Genic Therapy (LTCG, CHU Liège, Belgium) under GMP condition as previously described (33). UC-MSCs were isolated in our Hematology Research Unit (GIGA-I3, University of Liège, Belgium). Umbilical cords were provided by the maternity ward of the Center Hospitalier du Bois de l'Abbaye (Liège, Belgium), with informed consent of the mothers. Briefly, umbilical cord segments of approximately $5 \mathrm{~cm}$ were cut longitudinally to increase the contact area and plated onto a plastic surface for 5 days in Dulbecco's Modified Eagles Medium-Low Glucose with Glutamax (DMEM-GLX, Fisher-Bioblock, Invitrogen, Merelbeke, Belgium) supplemented with $10 \%$ gamma-irradiated Fetal Bovine Serum (FBS, Hyclone, Perbio Sciences, Utah, USA) and antibiotics (Penicillin/Streptomycin [P/S]). After 5 days, the cord segments were removed and the culture was pursued until subconfluency. AT-MSCs were provided by the Endocrine Cell Therapy unit of the Cliniques Universitaires Saint-Luc (Brussels, Belgium), and produced as previously described (34).

All MSCs were cryopreserved at passage 2 or 3 , then thawed and cultured 1-2 week(s) before trypsinization and injection to mice or use in in vitro experiments.

\section{MSC / PBSC Co-Cultures}

MSCs $\left(1 \times 10^{4}\right.$ or $\left.2 \times 10^{4}\right)$ were plated in flat-bottom 96-well plates (Becton-Dickinson) in RPMI 1,640 medium supplemented with $10 \% \mathrm{FBS}$, penicillin $(100 \mathrm{U} / \mathrm{ml})$, streptomycin (100 mg/ml), l-glutamine (2 mM) (all from Lonza), sodium pyruvate $(100 \mathrm{mM})$, non-essential amino acids $(100 \mathrm{mM})$, and $\beta$-mercaptoethanol $\left(5 \times 10^{-5} \mathrm{M}\right)$ (all from Gibco, Merelbeek, Belgium). For inflammatory stimulation, MSCs were incubated with IFN $\gamma 10 \mathrm{ng} / \mathrm{ml}$ and $\mathrm{TNF} \alpha 15 \mathrm{ng} / \mathrm{ml}$ during $40 \mathrm{~h}$ before harvest. For PBMC proliferation assays, MSCs were irradiated at 22 Gy using a 137Cs source (GammaCell 40, Nordion, Ontario, Canada) after 4-h incubation to reduce their proliferation. Allogeneic human PBMCs were isolated from blood samples of healthy volunteer donors by Ficoll Paque ${ }^{\mathrm{R}}$ Plus density gradient. For lymphocyte proliferation assays, PBMCs were stained with CFSE using a CellTrace CFSE Cell Proliferation Kit (Thermofisher) according to the manufacturer's instructions. PBMCs $\left(1 \times 10^{5}\right)$ were added to wells in a total volume of 200 $\mu l$ containing or not irradiated MSCs, in the presence of antiCD3/CD28 microbeads (Invitrogen, Dynal A/S, Oslo, Norway) at a bead/cell ratio of 1:1 in proliferation assays and 1:5 in the other experiments. Recombinant human IL-2 300 U/ml (PeproTech,
USA) was added for the regulatory T-cell (Treg) assays. Cells were incubated at $37^{\circ} \mathrm{C}$ during 3-7 days depending on the assay, and collected at different time points for FACS analysis.

\section{Humanized Mouse Model of Graft-vs.-Host Disease}

All experimental procedures and protocols used in this investigation were reviewed and approved by the Institutional Animal Care and Use Committee of the University of Liège, Belgium (Certification No. 1480). Animal welfare was assessed at least once per day. We used NOD-scid IL-2R $\gamma$ null (NSG) mice expressing the HHD construct designed for the expression of human HLA-A0201 covalently bound to human $\beta 2$ microglobuline (NSG-HLA-A2/HHD) (Jackson laboratory) (35), aged from 8 to 12 weeks at the start of the experiments. Both male and female mice were used, and their repartition was balanced between treatment groups in each cohort. They received a sublethal (2 Gy) irradiation (137Cs source gamma-cell irradiator 40, Nordon, Canada) on day -1 , followed on day 0 by an intravenous (i.v.) injection (lateral tail vein) of 1 or $1.5 \times 10^{6} \mathrm{PBMCs}$ obtained from healthy mismatched (non-HLA-A2) volunteers to induce GVHD. We previously reported that infusion of PBMCs from non-HLA-A2 donors induced stronger GVHD than injection of PBMCs from HLA-A2 ${ }^{+}$donors in NSG-HLA-A2/HHD mice (31). Hence, in this model, GVHD is both xenogeneic (human to mouse) and allogeneic (non-HLA-A2 donor to HLA-A2 recipient). We used PBMCs from 3 different donors for the 3 cohorts to account for inter-donor variability (all groups of mice were transplanted with the same donor within each cohort). Mice (usually 8 per group) were treated with 3 i.v. injections of BM-, UC- or AT- MSCs diluted in $200 \mu \mathrm{L}$ PBS, or the same volume of PBS (control group) on days 14, 18, and 22. In the second cohort, one group received i.p. injections of $4 \mathrm{mg}$ tocilizumab (RoActemra ${ }^{\circledR}$, Roche) $2 \mathrm{~h}$ before each MSC infusion. GVHD severity was assessed by a scoring system that incorporates four clinical parameters-weight loss, posture (hunching), mobility and anemia-each parameter receiving a score of 0 (absent) to 2 (maximum), as previously described $(31,36,37)$. Mice were monitored daily during the experiments and assessed for GVHD score three times a week. Mice reaching a GVHD score of 6/8 were euthanized in agreement with the recommendation of our ethical committee. Final scores for animals reaching the limit score were kept in the data set for the remaining time points (last value carried forward). Blood samples were collected by tail puncture at day 28 and day 42 after human cell transplantation for flow cytometry analysis. If enough blood could be harvested from mice, cells were counted with a Sysmex XS-800i ${ }^{\circledR}$. In the third cohort, additional blood samples were collected 1 day after the 2nd MSC infusion for cytokine measurements.

\section{Flow Cytometry}

For peripheral blood collected from mice, samples were first depleted of erythrocytes using RBC lysis buffer (eBioscience, San-Diego, CA) according to the manufacturer's instructions. Cells were stained with various combinations of fluorescenceconjugated anti-human antibodies. For surface staining, cells were incubated with surface antibodies for $20 \mathrm{~min}$ at $4^{\circ} \mathrm{C}$ in the 
dark and washed twice with PBS/3\% FBS (Lonza). Intracellular staining was performed by using the FoxP3 Staining Buffer Set (eBioscience), according to the manufacturer's instructions. For intracellular cytokine staining, cells were first stimulated for $4 \mathrm{~h}$ at $37^{\circ} \mathrm{C}$ and $5 \% \mathrm{CO} 2$ in RPMI supplemented with $10 \%$ FBS and in the presence of PMA/ionomycin, brefeldin $\mathrm{A}$ and monensin (Cell Stimulation Cocktail + Protein Transport Inhibitors, eBioscience), according to the manufacturer's instructions. Data were acquired on a FACSCanto II or LSRFortessa flow cytometer (Becton Dickinson) and analyzed with the Flowjo software v10.0.7r2 (Tree Star Inc., Ashland, OR). Data from the flow cytometry analyses of blood samples of mice in the third cohort were also analyzed with FlowSOM. Data were compensated, then human $\mathrm{CD} 45^{+}$cells were manually gated with FlowJo v10, concatenated within the same group and analyzed with the Bioconductor package FlowSOM.

\section{Cytokine Measurement}

Mouse sera were collected with SST Tubes (BD Microtainer), centrifuged for $10 \mathrm{~min}$, then stored at $-80^{\circ} \mathrm{C}$. The concentration of human cytokines was determined after 2-fold serum dilution, by using a custom Magnetic Luminex Performance Assay (R\&D Systems, USA). Procedures were performed according to the manufacturer's instructions. Results were acquired on BioPlex System and analyzed with Bio-Plex Manager Software 4.0 (Biorad Laboratories).

\section{Rotational Thromboelastometry (ROTEM)}

MSCs from 3 different healthy donors (2 donors for ATMSCs) were thawed and cultured 1 week before the experiment. Samples of blood from 3 healthy volunteers were collected in citrated tubes. PBS was used as a negative control. MSCs were incubated $10 \mathrm{~min}$ in citrated whole blood at a concentration of $10^{6}$ cells $/ \mathrm{ml}$, then $\mathrm{CaCl}_{2}$ (Star-TEM) was added to the sample and measurements of coagulation activation was made using ROTEM $^{\circledR}$ (NATEM assay) according to the manufacturer's procedure. Samples were kept at $37^{\circ} \mathrm{C}$ during the procedure.

\section{Statistical Analyses}

Data are presented as individual observations (with or without median) or as median with range. For survival analyses, comparisons between groups were made with the log-rank test and with multivariate Cox models adjusted for experiment (one donor PBMC was used per experiment), mouse gender and mouse weight at transplantation. Survival curves were plotted using Kaplan-Meier estimates. Evolution of GVHD scores over time was analyzed with a repeated ordinal logistic model (GENMOD), with adjustment for experiment, mouse gender, and mouse weight at transplantation. GVHD score at death were carried forward after death. For in vivo analyses, comparisons between control group and either BM-MSC, UC-MSCs, or ATMSC groups were made with one-way analysis of variance tests with Dunnett's post-hoc procedure. Analyses were adjusted for experiment. For in vitro analyses, comparisons between control group and either BM-, UC-, or AT-MSC groups were made using repeated measure one-way analysis of variance test with Dunnett's post-hoc procedure (except for inhibition of lymphocyte proliferation: comparisons between BM-, UC-, and AT-MSC groups were made using repeated measure one-way analysis of variance test with Bonferroni post-hoc procedure) and comparisons between resting and primed MSC groups were made with paired $t$-tests. To normalize their distribution, some variables underwent prior logarithmic transformation. Results were considered significant at the $5 \%$ level $(p<0.05)$. Statistical analyses were carried out with RStudio v1.1.453 and Graphpad Prism 5.0 (Graphpad Software, USA).

\section{RESULTS}

\section{Impact of MSCs on PBMC Proliferation in vitro}

We compared the ability of MSCs to suppress PBMC proliferation in vitro at two different MSC/PBMC ratios (1/5 and 1/10). Lymphocytes were stimulated with anti-CD3/CD28 beads, mimicking stimulation by APCs as well as early events occurring in human PBMCs infused in NSG-HLA-A2/HHD mice (31). We repeated the experiment with MSCs from 2 to 3 different donors and PBMCs from 2 to 4 different donors for each MSC donor. Some of these experiments were realized in triplicate, and mean values were used for statistical analysis. BM-, UC-, and AT-MSCs were either resting or primed $\left(\mathrm{BM}^{*}, \mathrm{UC}^{*}\right.$, and $\left.\mathrm{AT}^{*}\right)$ by IFN $\gamma$ and $\mathrm{TNF} \alpha$. This is relevant since previous reports have demonstrated that these cytokines have a profound impact on MSCs (38-42) and since high levels of IFN $\gamma$ and $\mathrm{TNF} \alpha$ are present in the sera of NSG-HLA-A2/HHD mice infused with human PBMCs (31). The impact of MSCs on PBMC proliferation was calculated as percentage suppression compared with the proliferative response in the positive control without MSCs.

After $72 \mathrm{~h}$ of co-culture, resting BM- and AT- MSCs were more potent to inhibit PBMC proliferation compared to resting UC-MSCs at a ratio of $1 / 5$ (median inhibition 51 vs. 48 vs. $9 \%, p=0.0001$ ) and $1 / 10$ (median inhibition 30 vs. 27 vs. $3 \%, p=0.0005$ ) (Figure 1). As previously observed, BM-, AT- and UC-MSCs primed with IFN $\gamma$ and $\mathrm{TNF} \alpha$ were more potent to inhibit PBMC proliferation than resting MSCs at both MSC/PBMC ratios. Interestingly, primed MSCs from various origins had a comparable potency to inhibit PBMC proliferation (Figure 1). These data suggest that, in the context of CD3/CD28 stimulation, PBMC proliferation is potently inhibited by BM-, UC-, and AT-MSCs primed with IFN $\gamma$ and TNF $\alpha$. Without that inflammatory priming, only BM- and AT-MSCs inhibited PBMC proliferation at these low MSC/PBMC ratios.

\section{Impact of MSCs on Lymphocyte Activation in vitro}

We also analyzed the effects of BM-, UC-, and AT-MSCs on lymphocyte activation in vitro. PBMCs were cultured with MSCs, either resting (BM, UC, and AT-conditions) or primed with IFN $\gamma$ and $\mathrm{TNF} \alpha\left(\mathrm{BM}^{*}, \mathrm{UC}^{*}\right.$, and $\mathrm{AT}^{*}$ conditions), or without MSCs (control condition), at a MSC/PBMC ratio of 1/10. Expression of early (CD69), late (CD25) and very late (HLA-DR) markers of activation of $\mathrm{CD}^{+}{ }^{+}$and $\mathrm{CD}^{+}$cells was analyzed after $6,24,48$, 72 , and $96 \mathrm{~h}$. The experiment was repeated twice with MSCs and 

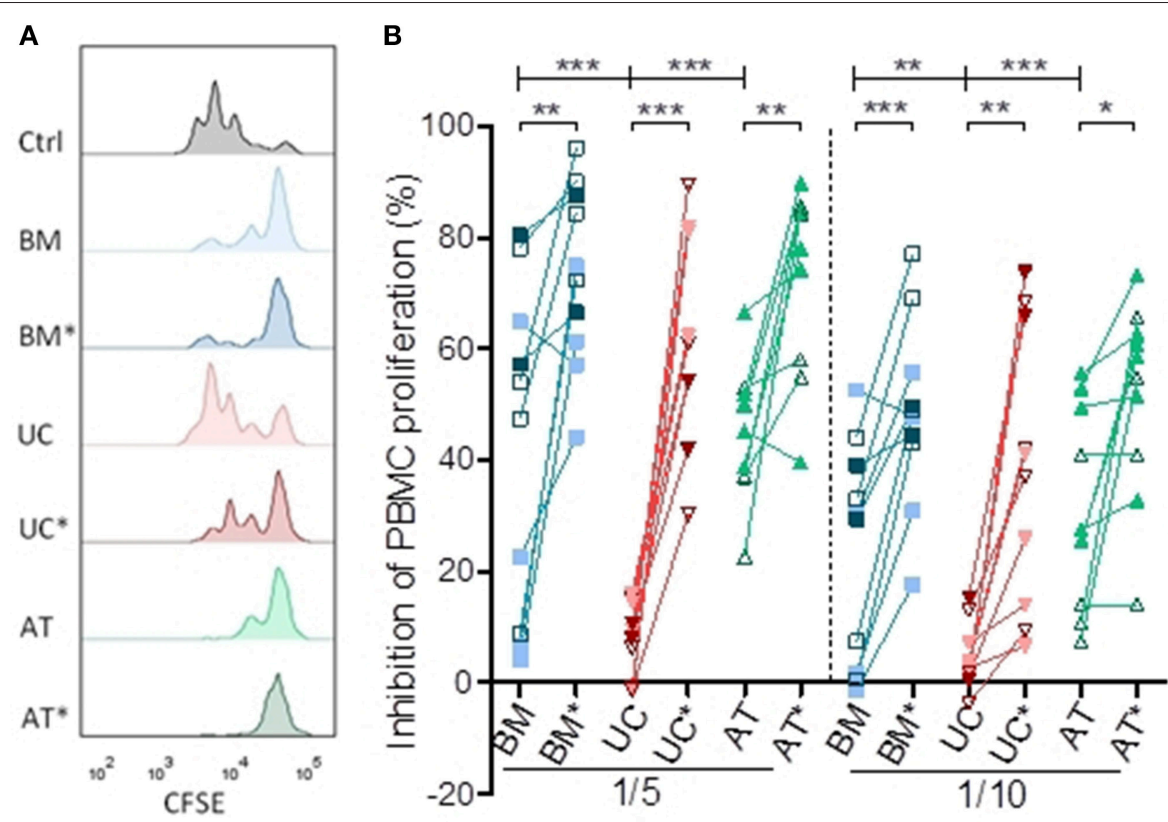

FIGURE 1 | Inhibition of lymphocyte proliferation in vitro. PBMCs were cultured with or without MSCs in the presence of anti-CD3/CD28 microbeads for 3 days, at MSC/PMBC ratios of 1/5 and 1/10. Proliferation of PBMCs was assessed using a CellTrace CFSE Cell Proliferation Kit. The effect of MSCs on PBMC stimulation responses was calculated as percentage suppression compared with the proliferative response in the positive control without MSCs. For inflammatory stimulation, MSCs were incubated with IFN $\gamma 10 \mathrm{ng} / \mathrm{ml}$ and TNF $\alpha 15 \mathrm{ng} / \mathrm{ml}$ during $40 \mathrm{~h}$, prior to harvest (BM*, AT*, and UC*). (A) Representative plots of PBMC proliferation in coculture with MSCs, assessed by CFSE dilution. (B) Inhibition of lymphocyte proliferation. Data are presented as individual observations (or mean value if the experiment was realized in triplicates). White, light, and dark symbols represents MSCs from different donors; each point represents a different MSC-PBMC couple. Differences between resting MSC groups and between primed MSC groups are calculated with repeated measure ANOVA with Bonferroni post-hoc procedures (only results with Bonferroni post-hoc tests are represented). Differences between resting and primed MSC groups were calculated with paired $t$-test $\left({ }^{\star} p<0.05,{ }^{* *} p<\right.$ $\left.0.01 ;{ }^{* \star *} p<0.001\right)$.

PBMCs from 2 different donors. The kinetics of PBMC activation by anti-CD3/CD28 beads resulted, as previously described (43), in a rapid and brief upregulation of the early activation marker CD69 within $24 \mathrm{~h}$, followed by a rapidly progressive and lasting expression of CD25, and a slowly progressive upregulation of HLA-DR (Supplementary Figure 1).

There was no major impact of MSCs on the kinetics of CD69 and CD25 expression on T cells except for a higher expression of CD69 in AT-MSC conditions at $96 \mathrm{~h}$ (Figures 2A-D). In contrast, HLA-DR up-regulation on both $\mathrm{CD}^{+}$and $\mathrm{CD} 8^{+}$lymphocytes was clearly impacted by MSC co-culture. Specifically, compared to the control condition, HLA-DR expression on $\mathrm{CD} 4^{+}$cells was significantly lower in the BM condition at 24,72 , and $96 \mathrm{~h}$ and in UC and AT conditions at 24, 48, 72, and $96 \mathrm{~h}$. The effect of MSC coculture on $\mathrm{CD}^{+}$cells was less pronounced but was still observed at the latest assessed time point $(96 \mathrm{~h})$ (Figures 2E-G). Interestingly, priming of BM-MSCs with IFN $\gamma$ and $\mathrm{TNF} \alpha$ resulted in an early upregulation of HLA-DR on both $\mathrm{CD}^{+}{ }^{+}$and $\mathrm{CD} 8^{+} \mathrm{T}$ cells, while this effect was not observed with primed UC- or AT-MSCs (Figures 2E,F).

Taken together, these data suggest that UC- and AT-MSCs exert a potent inhibitory effect on lymphocyte activation regardless of inflammatory priming, while BM-MSCs elicit transient lymphocyte activation when primed by inflammatory cytokines.

\section{Impact of MSCs on T Helper Subsets in vitro}

We also studied the impact of MSC co-culture on lymphocyte subset proportions in vitro. We analyzed the effect of BM-, UC-, and AT-MSCs on $\mathrm{T}$ helper subset proportions when PBMCs were cultured with anti-CD3/CD28 beads, at a MSC/PBMC ratio of $1 / 10$, for 7 days. For Treg $\left(\mathrm{CD} 4^{+} \mathrm{CD} 25^{+} \mathrm{FoxP}^{+}\right)$ subset analyses, we added IL- 2 in the culture media. The experiment was repeated three times with MSCs and PBMCs from 2 to 4 different donors, and we analyzed the expression of $\mathrm{CD}_{2} 5^{+}$and FoxP3 ${ }^{+}$as well as IL-10, IFN $\gamma$, IL-4, and IL-17 at day 7 (Supplementary Figure 2).

Co-culture of PBMCs with MSCs increased the percentage of $\mathrm{CD}^{+}{ }^{+} \mathrm{CD} 25^{+} \mathrm{FoxP}^{+}$cells (Tregs) at day 7 compared to controls. This reached statistical significance with UCand AT-MSCs (Figure 3A). Coculture of PBMCs with BM- and AT-MSCs increased the proportion of $\mathrm{IL}_{-} 10^{+}$ $\mathrm{CD}^{+}$cells (respectively median 6.8 and 6.5 vs. $3.3 \%$ in control condition) (Figure 3B). The proportions of Th1 $\left(\mathrm{IFN} \gamma^{+} \mathrm{CD} 4^{+}\right)$and Th2 (IL4 $\left.{ }^{+} \mathrm{CD} 4^{+}\right)$cells were not significantly impacted by MSC coculture compared to the control condition (Figures 3C,D). However, the percentage of $\mathrm{Th} 17\left(\mathrm{IL}_{17}{ }^{+} \mathrm{CD} 4^{+}\right)$cells was lower when PBMCs were cultured with UC-MSCs compared to controls (Figure 3E). 

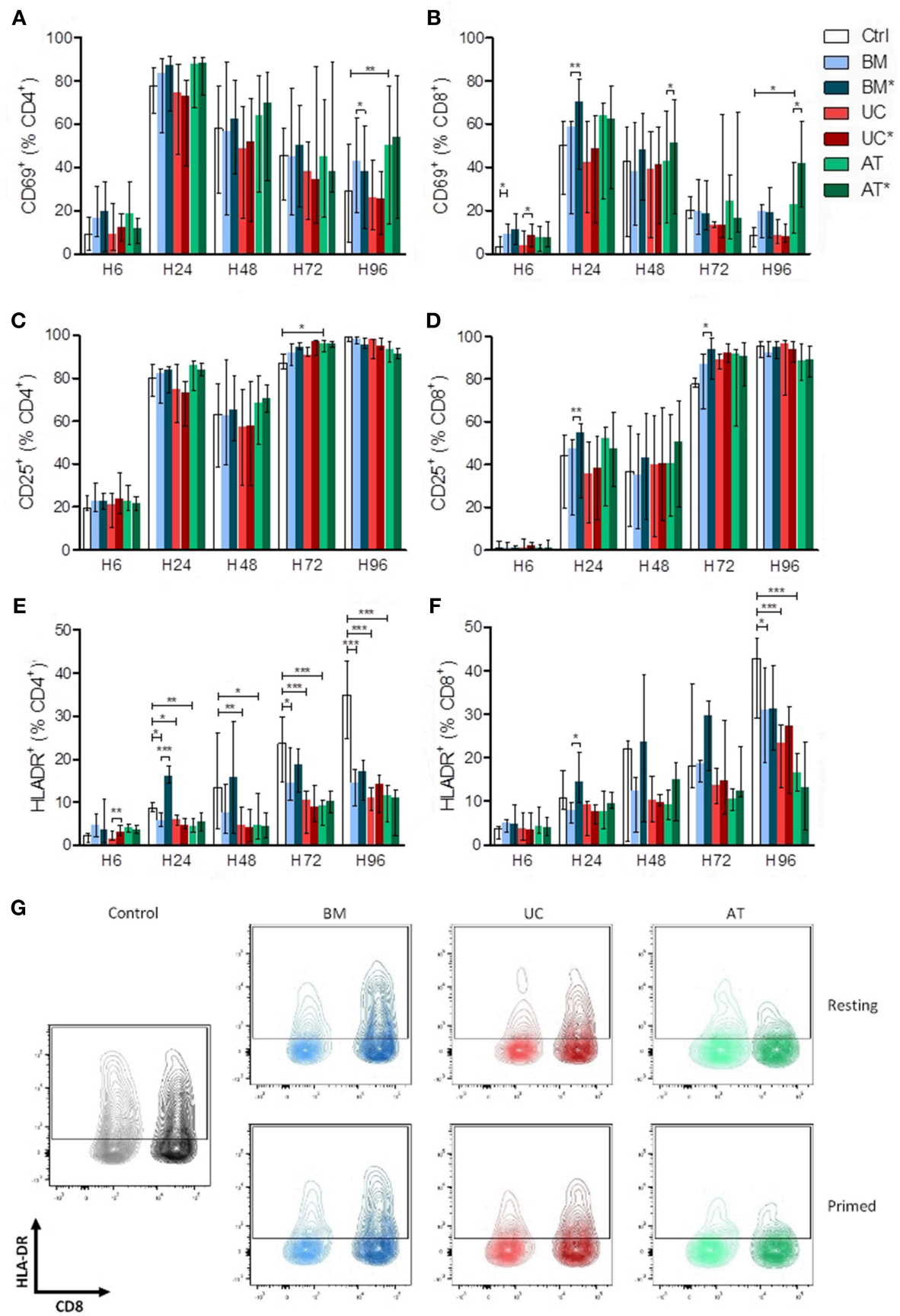

FIGURE 2 | Lymphocyte activation (measured by CD69, CD25, and HLA-DR expression) in co-culture with MSC. PBMCs were cultured with or without MSCs in the presence of anti-CD3/CD28 microbeads for 4 days, at a MSC/PBMC ratio of 1/10. For inflammatory stimulation, MSCs were incubated with IFN $\gamma 10$ ng/ml and TNF $\alpha$ $15 \mathrm{ng} / \mathrm{ml}$ during $40 \mathrm{~h}$, prior to harvest $\left(\mathrm{BM}^{*}, \mathrm{AT}^{*}\right.$, and $\left.\cup \mathrm{C}^{*}\right)$. Expression of (A,B) CD69, (C,D) CD25, and (E,F) HLA-DR on CD4 ${ }^{+}$and CD8 ${ }^{+}$lymphocytes was analyzed after 6, 24, 48, 72, and $96 \mathrm{~h}$ by FACS. (G) Representative plots of HLA-DR expression at H96 in CD4+ and CD8 ${ }^{+}$lymphocytes. Data are presented as median with range. Differences between control, and BM, AT, or UC groups are calculated with repeated measure ANOVA with Dunnett's post-hoc procedures (only results of Dunnett's post-hoc tests are represented). Differences between resting and primed MSC groups were calculated with paired $t$-test $\left({ }^{\star} p<0.05\right.$, ${ }^{\star \star} p<0.01$; $\left.{ }^{\star \star \star} p<0.001\right)$

In summary, co-culture of PBMCs with BM-MSCs increased the proportion of $\mathrm{IL} 10^{+} \mathrm{CD} 4^{+}$cells, while UC-MSCs resulted in a higher Treg proportion and lower Th17 proportions, and ATMSCs increased both Tregs and $\mathrm{IL}_{10}{ }^{+} \mathrm{CD} 4^{+}$cells proportions.
Impact of MSC Therapy on GVHD in Humanized Mouse Model

Mice received sub-lethal (2 Gy) irradiation on day-1, followed by an i.v. injection of PBMCs obtained from healthy mismatched 

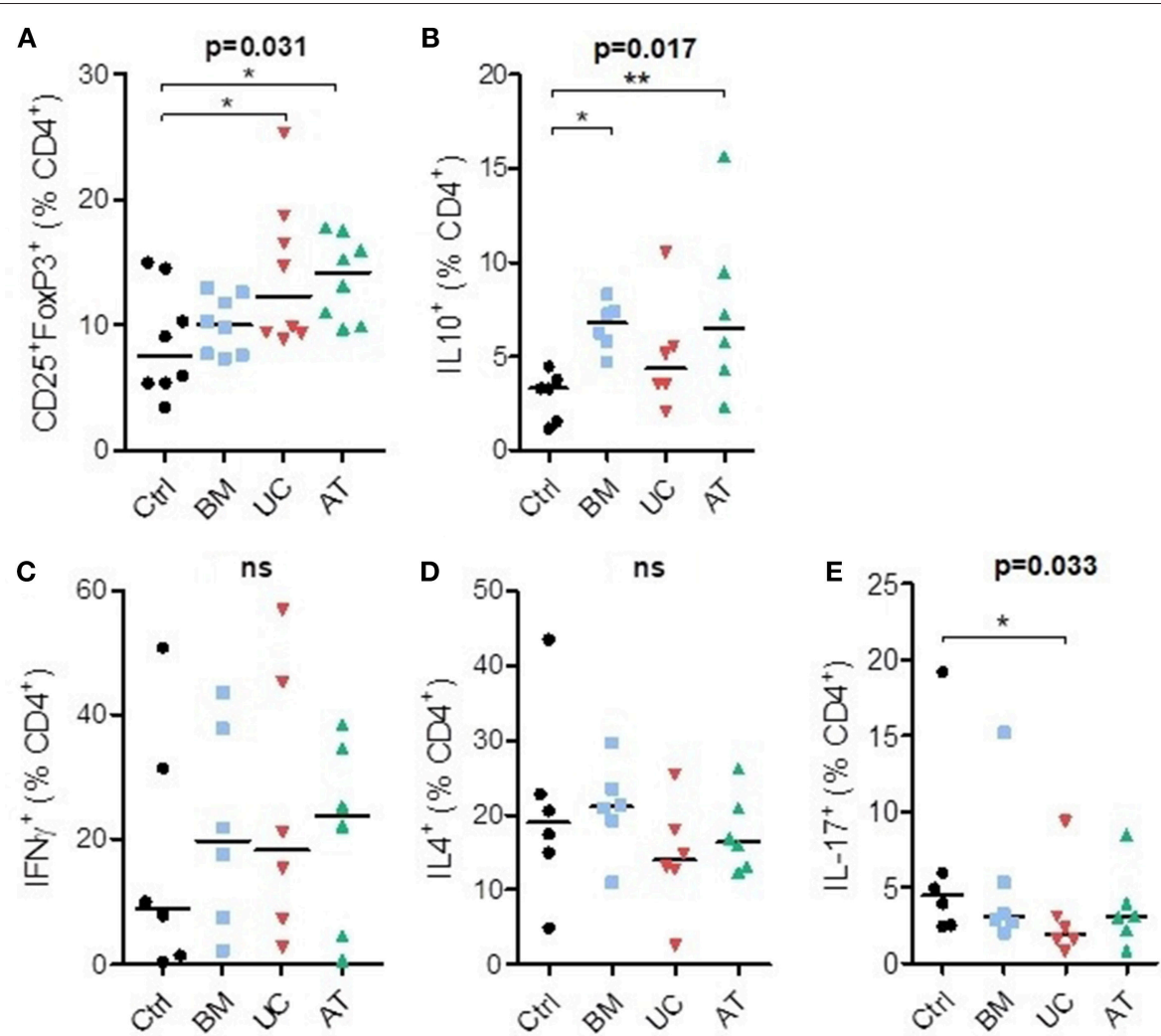

FIGURE 3 | T-helper lymphocyte subsets in co-culture with MSC. PBMCs were cultured with or without MSCs in the presence of anti-CD3/CD28 microbeads (and

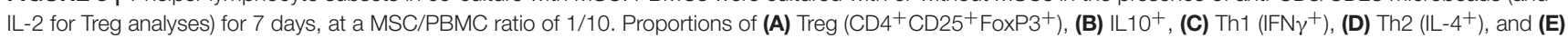
Th17 $\left(\mathrm{IL}-17^{+}\right)$cells were evaluated at day 7 by FACS. Data are presented as individual observations (or mean value if the experiment was realized in duplicates) with median. Global $p$-values (repeated measure ANOVA-1) are shown as well as comparisons between MSC groups and controls with Dunnett's post-hoc procedure $\left({ }^{*} p<0.05 ;{ }^{* *} p<0.01\right)$.

volunteers (non-HLA-A2) on day 0, and 3 i.v. injections of BMMSCs (BM group), UC-MSCs (UC group), or AT-MSCs (AT group) in $200 \mu \mathrm{L}$ PBS, or the same volume of PBS alone (control group) on days 14,18 , and 22 (8 mice per group per experiment). In order to prevent inter-donor variability, the experiment was replicated three times with three different donors.

In the first cohort, mice received $1 \times 10^{6} \mathrm{PBMCs}$, resulting in the development of an acute GVHD that was lethal in all control mice. We started to infuse MSCs $\left(1 \times 10^{6} \mathrm{MSC} /\right.$ dose/mouse $)$ or PBS at day 14, when mice showed the first signs of GVHD. Control mice started to die 15 days after the 3rd infusion (from day 39). We observed an earlier mortality in the MSC groups, especially in the AT group in which one mice died at the time of the third MSC infusion, probably of pulmonary embolism (although no necropsy was performed to prove it). However, UCMSC therapy eventually resulted in a trend for a longer median survival (63 vs. 44,49 , and 43 days in the control, BM and AT groups, respectively, ns) (Figure 4A).

Given the results of the first cohort, we elected to slightly increase the number of PBMCs infused in order to induce a stronger GVHD. Further, we elected to increase the MSC dose to $2 \times 10^{6} \mathrm{MSC} /$ dose/mouse, except for the UC groups in which we compared 1 and $2 \times 10^{6} \mathrm{MSC} /$ dose/mouse (UC1 and
UC2 groups). Mice received $1.5 \times 10^{6} \mathrm{PBMCs}$ from another donor and developed GVHD that was lethal (from day 17) in approximately $75 \%$ of the mice. Further, since we had observed high serum human IL-6 levels following MSC infusion in NSG mice in a prior study (44), we also assessed the impact of an i.p. injection of $4 \mathrm{mg}$ tocilizumab, an anti-human IL-6 receptor antibody, $2 \mathrm{~h}$ before each MSC injection, in a sixth group of mice treated with $2 \times 10^{6} \mathrm{UC}$-MSCs (UC2-T group). Unfortunately, as observed in the first cohort of mice, AT-MSCs induced injectionrelated mortality in 3 mice. Specifically, following the first ATMSC injection on day 14 , the 2 nd mice receiving $2 \times 10^{6}$ AT-MSCs died of probable pulmonary embolism (unfortunately no necropsy was performed to confirm pulmonary embolism); hence the 6 remaining mice received $1 \times 10^{6}$ AT-MSCs. After the second injection, the 2 first mice given $2 \times 10^{6}$ AT-MSCs died of probable pulmonary embolism; hence the 5 remaining mice received $1 \times 10^{6}$ AT-MSCs for the second and the third injections, and there was no further acute mortality. Focusing on BM- and UC- MSCs, MSC therapy slightly delayed GVHD onset and increased median survival, but survival curves were not statistically different (median survival of 42, 59, and 59 days in the control, BM and UC2 groups, respectively). No dose effect was observed since survival was similar between mice treated 

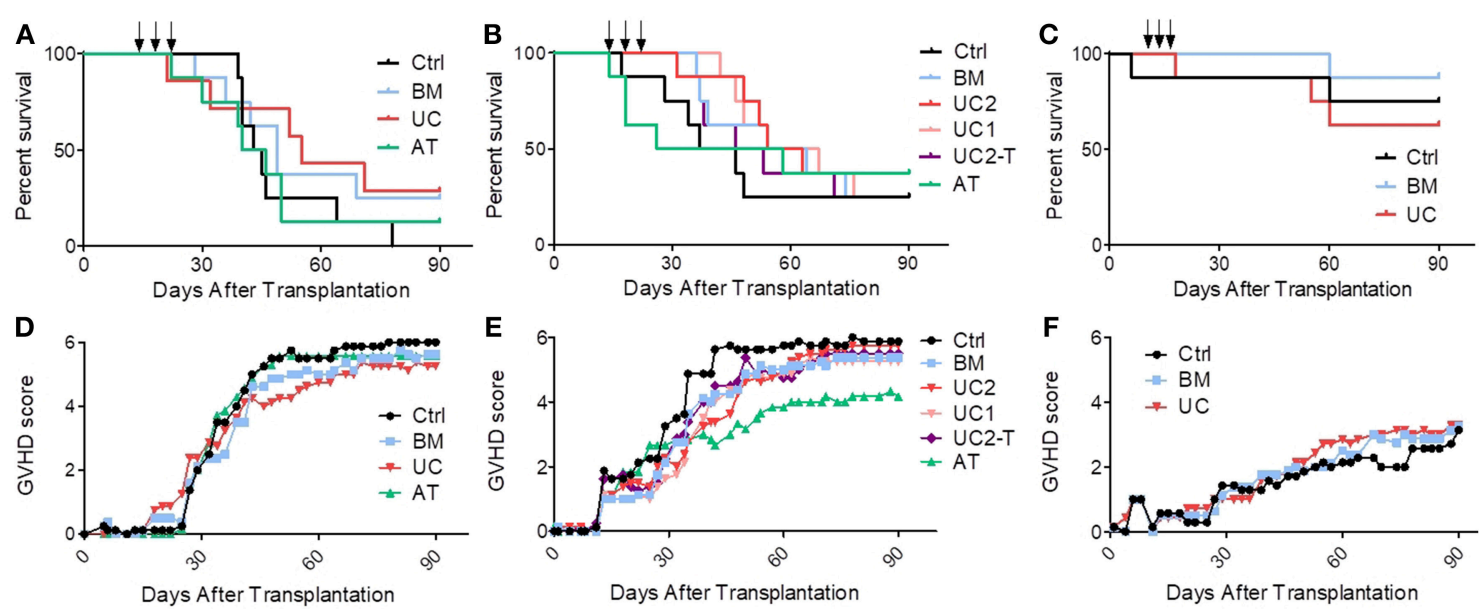

FIGURE 4 | Impact of MSC therapy on GVHD. After 2 Gy total body irradiation, NSG-HLA-A2 mice were transplanted on day 0 with $1-1.5 \times 10^{6}$ PBMCs and treated with 3 i.v., injections (arrows) of $1-2 \times 10^{6}$ MSCs derived from either BM, UC, or AT, or with PBS (control group) on days 14, 18, and 22. (A) Survival curves of mice from the 1 st cohort $\left(1 \times 10^{6}\right.$ PBMCs $-1 \times 10^{6}$ MSCs); $n=8$ mice per group. (B) Survival curves of mice from the 2 nd cohort $\left(1.5 \times 10^{6}\right.$ PBMCs $-2 \times 10^{6}$ MSCs in BM, AT, and UC2 groups, $1 \times 10^{6}$ MSCs in UC1 group - IP infusions of tocilizumab in UC2-T group); $n=8$ mice per group. (C) Survival curves of mice from the 3rd cohort ( $1 \times 10^{6}$ PBMCs $-1 \times 10^{6}$ MSCs); $n=8$ mice per group. (D-F) GVHD scores of mice from cohorts 1, 2, and 3 (data shown as means).

with 1 or $2 \times 10^{6}$ UC-MSCs (median survival 61 vs. 59 days, respectively). Finally, the adjunction of tocilizumab failed to enhance the efficacy of UC-MSC therapy (median survival 49 vs. 59 days in the UC2-T and UC2 groups, ns) (Figure 4B).

Given the high proportion of AT-MSC mice dying from MSC infusions, we elected to focus on BM-MSC and UC-MSC in the third cohort. Mice received $1 \times 10^{6}$ PBMCs from a third donor which induced this time a relatively mild GVHD. They were treated with $1 \times 10^{6} \mathrm{BM}$ - or UC-MSCs, or the same volume of PBS alone (control group) on days 14, 18, and 22, as in the first cohort. Only 4 of the 24 mice died of GVHD (1, 1 and 2 in the control, BM and UC groups, respectively). One mouse in the control group died on day 6 of unexplained cause without sign of GVHD, and another mouse died right after the 2nd UC-MSC injection, probably of pulmonary embolism (Figure 4C). Blood samples were collected on day 19 (1 day after the second MSC infusion) and serum levels of human IL-6, IL$10, \operatorname{IFN} \gamma$, and TNF $\alpha$ were analyzed by Bio-Plex. We observed slightly higher human IL-6 serum levels in mice treated with UC-MSCs compared to controls, but not in mice treated with BM-MSCs (median 0.0, 0.4, and $3.2 \mathrm{pg} / \mathrm{ml}$ in the control, BM and UC groups, respectively). No differences in serum levels of human IFN $\gamma$ (a marker of GVHD severity), TNF $\alpha$ and IL10 were observed between the 3 groups at this early time-point (Supplementary Figure 3).

In order to further assess the impact of BM-MSCs or UCMSCs on GVHD in the 3 cohorts combined, we built a Cox model adjusted for experiment (donor), mouse gender and mouse weight. We elected not to include AT-MSCs in the model given its high rate of injection-related mortality. We did not either include the data from the UC-Tocilizumab group. The multivariate model confirmed that intravenous MSC infusions failed to significantly increase survival (hazard ratio $[\mathrm{HR}]=0.59,95 \% \mathrm{CI}$
0.32-1.08; $P=0.087$ ) (Supplementary Table 1). In a sensitivity analysis using the same adjustments as described above, we compared survival in control vs. each MSC group separately. The results for the BM-MSC vs. control comparison was $\mathrm{HR}=0.63$ (95\% CI $0.30-1.34, P=0.24$ ) while the figures for the UCMSC vs. control comparison was HR $=0.56$ (95\% CI 0.28-1.10, $P=0.09$ ) (Supplementary Table 2). In concordance with these results, GVHD scores were not significantly lower in the MSC than in control mice (generalized estimating equation [GEE] estimate $-0.7,95 \% \mathrm{CI}-1.8-0.3, P=0.18$ ) (Figures $4 \mathrm{D}-\mathbf{F}$ ).

\section{Characterization of Circulating Human Lymphoid Cells in Mice Treated With MSCs}

We also analyzed circulating human lymphocytes in the peripheral blood of mice on days 28 and 42 post-transplantation. Proliferation of human lymphocytes was not significantly influenced by MSC therapy, as percentages of human $\mathrm{CD} 45^{+}$ lymphoid cells, CD4/CD8 ratio and expression of Ki67 in $\mathrm{CD}^{+}$and $\mathrm{CD} 8^{+}$cells, were not significantly different in MSC groups compared to the control group (Supplementary Figure 4 including data from the 3 cohorts).

We also analyzed the impact of MSC therapy on Treg proportions (in all 3 cohorts) and intracellular cytokine expression in conventional (non-Treg) $\mathrm{CD} 4^{+}$(Tconv) and $\mathrm{CD} 8^{+}$ cells (in cohorts 2 and 3). Treg frequencies remained low in all groups, although they were possibly slightly higher in the UC-MSC group on day 28 after transplantation (Figure 5A and Supplementary Figure 5). On day 28, there was also a trend toward a higher expression of IL-10 in CD8 ${ }^{+} \mathrm{T}$ cells (but not in $\mathrm{CD}^{+} \mathrm{T}$ cells) in the BM group (median $5.4 \%$ vs. 2.7 and $2.3 \%$ in the control and UC groups). On day 42 , we observed a significant increase in the percentages of $\mathrm{IL}-10^{+} \mathrm{CD} 4^{+}$and $\mathrm{IL}-10^{+} \mathrm{CD} 8^{+}$ cells in the BM group compared to the control group (IL- $10^{+}$ 

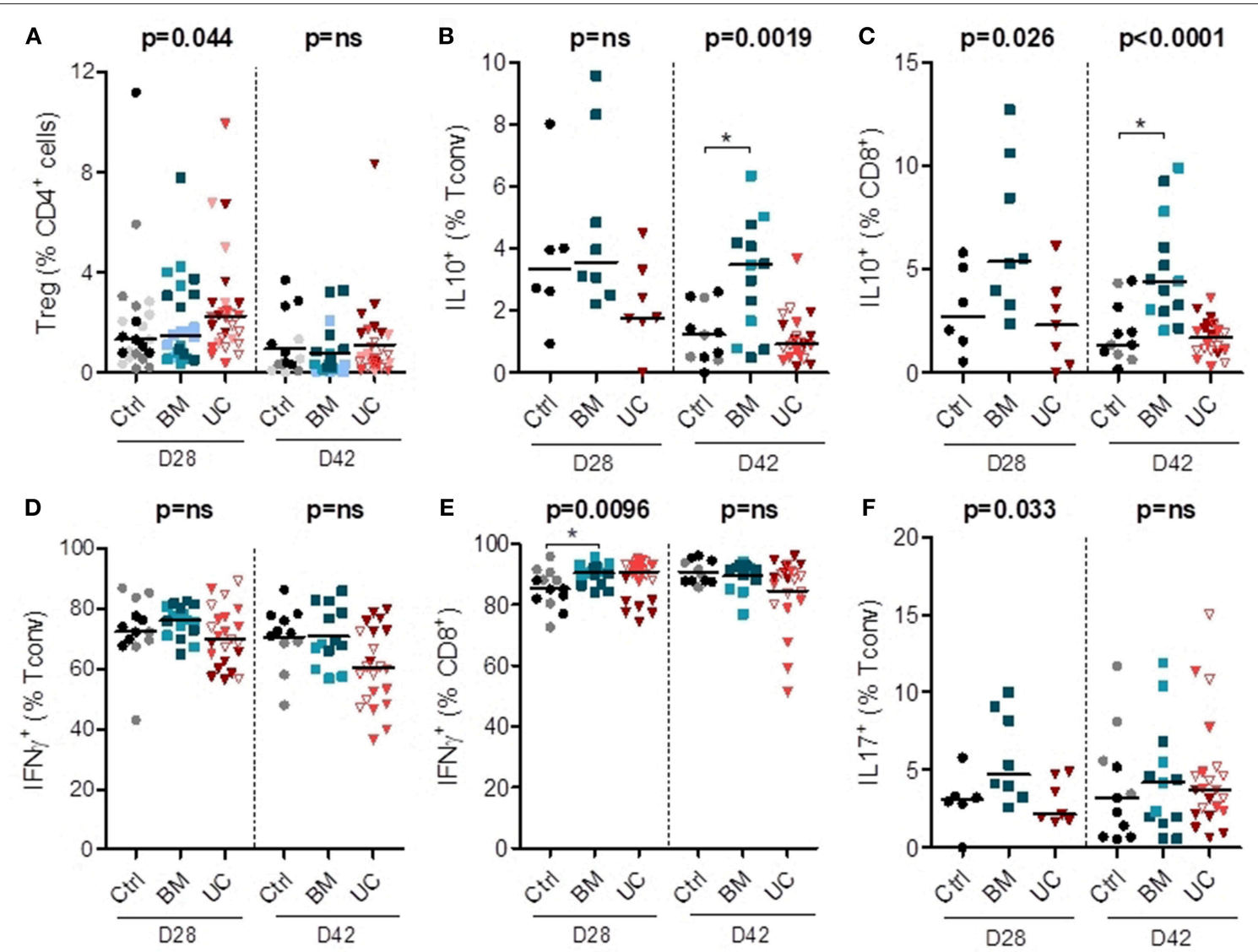

FIGURE 5 | Circulating human lymphoid cell subsets in peripheral blood of mice on days 28 and 42 after transplantation. After 2 Gy total body irradiation, NSG-HLA-A2 mice were transplanted on day 0 with 1-1.5 $\times 10^{6}$ PBMCs and treated with 3 i.v. injections of 1-2 $\times 10^{6}$ MSCs derived from either BM or UC, or with PBS (control group) on days 14, 18, and 22. Peripheral blood samples were collected on days 28 and 42 after transplantation for flow cytometry analyses, including analyses of the proportions of (A) Tregs $\left(\mathrm{CD} 25^{+} \mathrm{FoxP}^{+}\right)$among CD4 ${ }^{+}$cells, (B,C) human Tconvs and CD8 $8^{+}$cells expressing IL-10, (D-E) human Tconv and CD8 ${ }^{+}$ cells expressing IFN $\gamma$, and (F) human Tconv expressing IL-17. Data are presented as individual observations with median. Light, medium, and dark-colored symbols represent cohorts 1, 2, and 3, respectively, with empty symbols representing the lower dose UC group of the 2nd cohort. Global $p$-values (adjusted for experiment) are shown as well as comparisons between MSC groups and controls with Dunnett's post-hoc procedure $\left.{ }^{*} p<0.05\right)$. Prior logarithmic transformation was applied for Tregs on days 28 and 42 , and for $\mathrm{IL} 10^{+}$Tconv and $\mathrm{IL} 10^{+} \mathrm{CD} 8^{+}$cells on day 42 .

$\mathrm{CD}^{+}$: median 3.5 vs. $1.2 \%$; IL- $10^{+} \mathrm{CD}^{+}$: median 4.4 vs. $\left.1.4 \%\right)$ (Figures 5B,C).

We also analyzed the impact of MSC therapy on proinflammatory IFN $\gamma$ and IL-17 secreting cells (in cohorts 2 and 3). There was no significant impact of MSC therapy on the proportion of Th1 (IFN $\gamma^{+}$Tconv) cells on days 28 and 42 post-transplantation (Figure 5D and Supplementary Figure 5). We observed a higher proportion of IFN $\gamma^{+} \mathrm{CD}^{+}$cells in the $\mathrm{BM}$ group compared to the control group on day 28 post-transplantation (median 91 vs. $85 \%$ ), while no significant difference was observed on day 42 (Figure 5E). We also observed a trend toward a higher proportion of Th17 (IL17 ${ }^{+}$Tconv) cells in the BM group on day 28 (median 4.7 vs. 3.1 and $2.1 \%$ in control and UC groups, respectively), but no significant difference on day 42 post-transplantation (Figure 5F). Finally, there was no difference in the proportions of $\mathrm{CD}^{+}{ }^{+}$and $\mathrm{CD} 8^{+}$cells expressing TNF $\alpha$ or IL-2 (Supplementary Figure 5).

Overall, these data suggest that UC-MSC therapy resulted in a trend toward a higher percentage of Tregs that nevertheless remained infrequent. BM-MSC therapy was associated with higher proportions and absolute numbers of IL- $10^{+}$cells, and also with a trend toward higher percentages of Th17 and IFN $\gamma^{+} \mathrm{CD} 8{ }^{+}$cells.

\section{In vitro Impact of MSCs on Coagulation}

In our in vivo studies, several mice died right after IV injection of MSCs, mostly AT-MSCs (4 mice), but also UC-MSCs (1 mouse). Since the procoagulant activity of MSCs has been described (45) and since death by pulmonary embolism has been reported in MSC-injected mice $(46,47)$, we compared the procoagulant activity of MSCs of the 3 origins by performing rotational thromboelastometry (ROTEM). We used PBS as negative control. The experiment was repeated 3 times with MSCs from 2 donors and blood from 3 other healthy donors. We measured clotting time (CT; time from test start until a clot firmness amplitude of $2 \mathrm{~mm}$ is reached), clot formation time (CFT; time between 2 and $20 \mathrm{~mm}$ amplitude of the clotting signal), maximum clot firmness (MCF) and $\alpha$-angle 

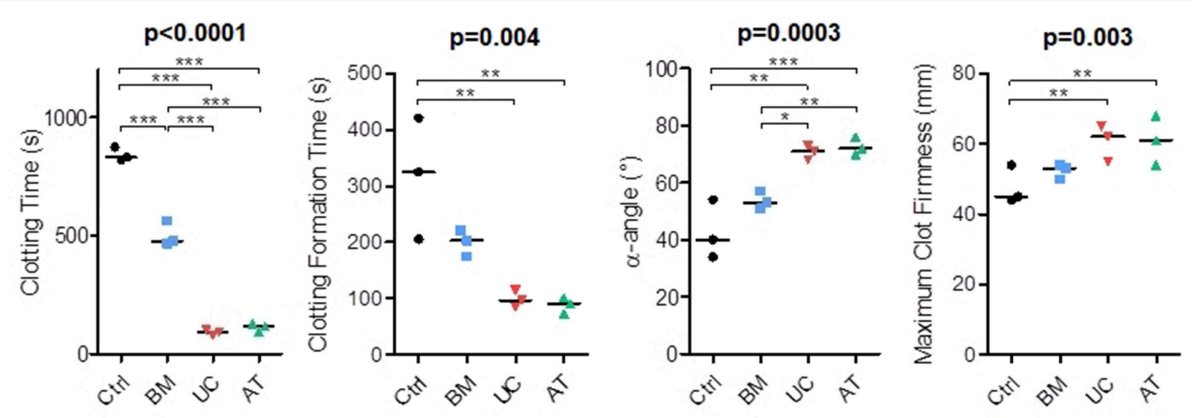

FIGURE 6 | Rotational thromboelastometry (ROTEM) with blood incubated with MSCs. MSCs derived from BM, UC, or AT were incubated 10 min in citrated whole blood at a concentration of $10^{6}$ cells $/ \mathrm{ml}$, then $\mathrm{CaCl}_{2}$ (Star-TEM) was added to the sample and measurements of coagulation activation were made using ROTEM ${ }^{\circledR}$ (NATEM assay). Data are presented as individual observations with median. Global $p$-values (repeated measure ANOVA-1) are shown as well as two-by-two group comparisons with Bonferroni post-hoc procedure $\left({ }^{*} p<0.05 ;{ }^{\star \star} p<0.01 ;{ }^{* \star *} p<0.001\right)$

(angle between the baseline and a tangent to the clotting curve through the $2 \mathrm{~mm}$ amplitude point). We observed that BMMSCs significantly reduced the clotting time when added to whole blood, but not as much as AT and UC-MSCs (median $831,477,117$, and $92 \mathrm{~s}$ in the control, BM, AT, and UC groups, respectively). Similarly, we observed a shorter clotting formation time and a higher maximum clot firmness with AT and UCMSCs compared to controls (median CFT 325, 203, 91, and $97 \mathrm{~s}$ and median MCF 45, 53, 61, and $62 \mathrm{~mm}$ in the control, $\mathrm{BM}, \mathrm{AT}$, and UC groups, respectively), with a significantly increased $\alpha$-angle compared to control and BM-MSCs (median $\alpha$-angle $40,53,72$, and $71^{\circ}$ in the control, BM, AT and UC groups, respectively) (Figure 6). These results show stronger coagulation activation by AT- and UC-MSCs compared to BMMSCs. These data suggest that the higher mortality observed after AT-MSC infusion compared to UC-MSC infusion is the result of not only a higher induction of coagulation. Cell size and/or different expression of adhesion molecules might be involved.

\section{DISCUSSION}

Fifteen years after the first publication of a clinical success of MSC therapy in acute GVHD by Le Blanc et al. (48), the controversy about their efficacy still remains. The complexity of the mechanisms of action of MSCs, as well as their heterogeneity and plasticity depending on many factors such as their origin, culture conditions, or inflammatory environment, combined with the complex pathophysiology of GVHD and the heterogeneity of administration protocols and patient characteristics have contributed to the discrepancies between studies. Most clinical trials have used BM-MSCs, but fetal tissue-derived MSCs have the advantage of being readily available and easy to collect from a waste product. Moreover, even though they share many biological characteristics, MSCs from different origins differ in several instances, including phenotype, secreatome, or immunomodulatory properties. MSC from alternative origins might therefore be a better option than BM-MSCs in GVHD.
In this study, we compared the efficacy of BM-, AT- and UC-MSCs injected at day 14, 18, and 22 post-transplantation in a model of mixed xenogeneic and allogeneic GVHD in NSG-HLA-A2 mice (31). Indeed, although important differences remain between GVHD in humanized NSG mouse models and in humans (such as the GVHD-target organs, the lack of interaction between some mouse cytokines and human cells, or the absence of donor APC engraftment in the NSG mouse model), important key mechanisms of GVHD pathogenesis are shared in human and xenogeneic GVHD. These include expansion of T-cell clones that recognize genetic disparities with the recipient (including murine MHC and human HLA-A2 in our model) following activation of their TCR and co-stimulation with host APCs. This results in upregulation of IL-2/STAT5, mTOR and Aurora kinase A pathways, and differentiation toward effector $\mathrm{T}$ cells able to secrete high amounts of TNF $\alpha$ and IFN $\gamma$ (31). Further, in contrast to mouse-to-mouse models of GVHD, humanized NSG(-HLAA2) models take into consideration donor genetic diversity when different PBMC donors are used. We elected to infuse $1 \times$ $10^{6}$ or $1.5 \times 10^{6}$ PBMCs from non-HLA-A2 donors following 2 Gy irradiation, since we previously reported that infusion of 1 $\times 10^{6}$ PBMCs from non-HLA-A2 donors induced a moderate GVHD in that model while administration of $2 \times 10^{6}$ PBMCs resulted in very severe GVHD (31). Indeed, infusion of the same dose of PBMCs from non-HLA-A2 donors consistently results in dramatically worse GVHD in NSG-HLA-A2 than in NSG mice (in which $2 \times 10^{6}$ to $5 \times 10^{6} \mathrm{PBMCs}$ are usually infused to induce GVHD when NSG mice are previously irradiated (31, 49-52). While the PBMC dose infused appeared adequate for experiment (donor) \#1 and \#2, it was suboptimal with the donor for the 3rd experiment since most of the control mice it that group survived beyond day 90 .

The main observation of our study was that MSC infusions failed to significantly prevent GVHD-related mortality. We cannot exclude that this was due to the sample size since the HR for mortality was in favor of (UC- and BM-) MSC therapy. However, the number of mice studied (a total of 24 control and 56 UC- or BM-MSC mice) was quite decent and several anti-GVHD prevention strategies proved to be efficient in NSG $(36,49,53)$ or 
NSG-HLA-A2 mice (53) using fewer mice per arm. Interestingly, despite their different in vitro ability to inhibit $\mathrm{T}$ cells, we did not observe significant differences in term of GVHD prevention by BM-, UC- or AT-MSCs. However, one may argue that UC-MSCs appear more efficient than BM-MSCs while the efficacy of ATMSCs was difficult to establish since several mice died of probable pulmonary embolism immediately after injection.

The dose and timing of infusion can always be discussed. However, we do not believe that the MSC dose was insufficient, since we infused a much higher dose of MSCs per kilogram compared to human studies, and since no differences were observed between the two UC-MSC dose groups in the second cohort. Although one could argue that the dose of MSC infused might have been too high, prior experimental studies have demonstrated better GVHD control with higher doses of MSC administered $(54,55)$. We elected to infuse MSCs from day 14 , when mice showed the first signs of GVHD. Indeed, several previous studies showed the inefficacy of resting unmanipulated MSCs when infused before GVHD onset, while IFN $\gamma$ primed MSCs prevented GVHD $(39,56)$. We hypothesized that the high circulating levels of TNF $\alpha$ and IFN $\gamma$ on day 14 in the NSG-HLAA2 model (31) could activate MSCs in vivo and increase their efficacy (as observed in vitro). Although starting MSC injection at day 14 might have been too late to prevent the aggressive and already engaged GVHD process, most trials of MSC therapy for acute GVHD have included patients in active (mostly steroidrefractory) acute GVHD.

Several prior articles have assessed the ability of BM- or cord blood (CB)-MSC to prevent or treat xenogeneic GVHD, although none compared the different MSC sources (44, 55-62) (Table 1). These studies differ in terms of source of MSC, schedule of MSC infusion as well as type/number/route of injection of human PBMCs. While some observed longer survival with MSCs (61), several others failed to demonstrate a significant benefit of MSCs as treatment of xenogeneic GVHD, as observed in the current study $(44,57)$.

Another observation of our in vivo studies was that intravenous infusion of $1 \times 10^{6}$ UC-MSCs was followed by a peak of serum IL-6 while infusion of the same number of BMMSCs did not. Our team previously showed that an i.p. infusion of $3 \times 10^{6}$ BM-MSCs resulted in a peak of serum IL-6 (44), but it is possible that the rise in IL-6 following the infusion of a smaller amount of MSCs did not reach the detection limit of the technique. This finding is consistent with several in vitro studies that have demonstrated a higher secretion of IL-6 from UCMSCs compared to BM-MSCs (63). Unfortunately, co-treatment with the anti-IL6R tocilizumab did not improve survival in mice treated with UC-MSCs, suggesting that this pro-inflammatory signal following UC-MSC infusions does not lessen their efficacy.

Flow cytometry analyses performed at day 28 posttransplantation revealed a trend toward an increased proportion of Tregs in mice treated with UC-MSCs, while BM-MSC therapy was associated with an increased proportion of $\mathrm{IL} 0^{+}$ lymphocytes, but also a trend toward an increased proportion of Th17 cells [whose role in xenogeneic GVHD in humanized mouse models is increasingly demonstrated $(37,64)]$ and IFN $\gamma^{+} \mathrm{CD}^{+}$cells. Most of these differences were lost at day 42 , confirming the limited long-term effects of MSC therapy in this GVHD model. However, a survival bias cannot be ruled out. Further, it should be emphasized that Treg frequencies, even in UC-MSC mice, remained low (in the range of $2.5 \%$ ) compared to what has been achieved in this model with Treg-promoting therapies such as azacitidine (53).

In in vitro co-culture, we observed that resting BM- and ATMSCs inhibited PBMC proliferation induced by anti-CD3/CD28 beads more potently than resting UC-MSCs. However, UCMSC efficacy was significantly enhanced by priming with IFN $\gamma$ and TNFa. Lymphocyte proliferation was inhibited by primed BM- and AT-MSCs to a little higher extent than by primed UC-MSCs, but the difference was not statistically significant. Conflicting results have been reported in the literature about the relative potency of BM-, AT- and UC-MSCs to inhibit Tcell proliferation, which seems to depend on the proliferative stimulus and priming of MSCs (65-67). In our murine model, this ability to inhibit lymphocyte proliferation did not translate into a reduction of $\mathrm{CD} 45^{+}$cell chimerism or Ki67 expression in $\mathrm{CD}_{4}^{+}$and $\mathrm{CD} 8^{+}$cells in MSC groups compared to controls, possibly because MSCs were infused after the early T-lymphocyte expansion phase. Similarly, a study in patients showed that Ki67 expression by lymphocytes was not modulated by MSC infusion (68).

MSCs also modulate the lymphocyte activation status. In a retrospective study on BM-MSC therapy for GVHD, MSCtreated patients had lower proportions of HLA-DR ${ }^{+} \mathrm{CD} 4^{+}$cells at day 90 and of $\mathrm{HLA}-\mathrm{DR}^{+} \mathrm{CD}^{+}$cells at day 180 postMSC infusions (68). We studied lymphocyte activation by anti$\mathrm{CD} 3 / \mathrm{CD} 28$ beads in co-culture with MSCs, and observed that UC- and AT-MSCs, whether resting or primed with IFN $\gamma$ and $\mathrm{TNF} \alpha$, induced the most potent down-regulation of HLA-DR on $\mathrm{CD}^{+}$and $\mathrm{CD}^{+}$cells. Importantly, co-culture of PBMCs with primed BM-MSCs resulted in a higher expression of the early activation marker CD69 and in a rapid upregulation of HLA-DR $24 \mathrm{~h}$ after activation of PBMCs. Similarly, other authors reported an early and transient upregulation of the co-stimulatory receptor CD28 on PHA-stimulated lymphocytes in co-culture with IFN $\gamma$-primed BM-MSCs but not with resting BM-MSCs or either resting or primed UC-MSCs (67). Therefore, unlike UC- and AT-MSCs, BM-MSCs in an inflammatory environment seem to induce a rapid pro-inflammatory reaction in contact with PBMCs before exerting their immunosuppressive properties. Accordingly, we observed at day 28 a higher expression of HLADR on Tconv cells in the BM group compared to the UC group in the third cohort.

The effects of MSCs on T lymphocytes are thought to combine not only suppression of pro-inflammatory cells but also induction of Tregs. In a retrospective study, BM-MSC treated patients had a higher proportion of Tregs at days 30 and 90 and of $\mathrm{IL} 10^{+} \mathrm{CD} 4^{+}$cells at day 90 , a lower percentage of Th17 cells at day 30, and a lower serum IFN $\gamma /$ IL-4 ratio (68). As mentioned above, in our murine model there was a trend toward a higher proportion of Tregs with UC-MSCs, while BM-MSCs induced higher levels of $\mathrm{IL}_{10} 0^{+} \mathrm{CD} 4^{+}$cells, but also tended to induce higher levels of Th17 cells. This is consistent with our observation that, in vitro, UC-MSCs 
TABLE 1 | Main prior studies of MSC as prevention/treatment of xenogeneic GVHD.

\begin{tabular}{|c|c|c|c|}
\hline References & $\begin{array}{l}\text { Xenogeneic mouse } \\
\text { model }\end{array}$ & $\begin{array}{l}\text { MSC source, dose, and schedule of } \\
\text { administration }\end{array}$ & Main observations \\
\hline \multicolumn{4}{|l|}{ PREVENTION } \\
\hline \multirow[t]{2}{*}{ Tisato et al. (57) } & $\begin{array}{l}\text { NOD/SCID, TBI } 2.5 \text { Gy, } \\
20 \times 10^{6} \text { hPBMCs IV }\end{array}$ & $3 \times 10^{6}$ CB-MSCs IV, day 0 & No change in weight loss and human T-cell expansion. \\
\hline & & $3 \times 10^{6}$ CB-MSCs IV, days $0,7,14$, and 21 & Decreased T-cell expansion, no GVHD development. \\
\hline $\begin{array}{l}\text { Gregoire-Gauthier } \\
\text { et al. (58) }\end{array}$ & $\begin{array}{l}\text { NSG, TBI } 3 \text { Gy, } 10 \times 10^{6} \\
\text { hPBMCs IP }\end{array}$ & $1 \times 10^{6}$ CB-MSCs IV, day 0 & $\begin{array}{l}\text { Significant increase in survival and reduction of clinical signs } \\
\text { of GVHD. }\end{array}$ \\
\hline \multirow[t]{4}{*}{ Bruck et al. (44) } & $\begin{array}{l}\text { NOD/SCID, TBI } 3 \text { Gy }+ \\
\text { aASGM1 Ab IP, } 200 \times 10^{6} \\
\text { hPBMCs IP }\end{array}$ & $2 \times 10^{6}$ BM-MSCs IV or IP, day 0 & No significant increase in survival. \\
\hline & $\begin{array}{l}\text { NSG, TBI } 2.5 \text { Gy, } 30 \times 10^{6} \\
\text { hPBMCs IP }\end{array}$ & $3 \times 10^{6}$ BM-MSCs IP, days $0,7,14$, and 21 & Slight survival advantage. \\
\hline & & $\begin{array}{l}3 \times 10^{6} \mathrm{IFN} \gamma \text {-BM-MSCs IP, days } 0,7,14 \\
\text { and } 21\end{array}$ & No significant increase in survival. \\
\hline & & $3 \times 10^{6}$ BM-MSCs IV, days 0,7, and 14 & No significant increase in survival. \\
\hline \multirow[t]{2}{*}{ Tobin et al. (56) } & $\begin{array}{l}\text { NSG, TBI } 2.4 \text { Gy, } 6.3 \times 10^{5} \\
\text { hPBMCs/g BW }\end{array}$ & $4.4 \times 10^{4}$ BM-MSCs/g BW, IV, day 7 & Increased survival, reduction of liver and gut pathology. \\
\hline & & $4.4 \times 10^{4} \mathrm{IFN} \gamma-\mathrm{BM}-\mathrm{MSC} / \mathrm{g} \mathrm{BW}, \mathrm{IV}$, day 0 & $\begin{array}{l}\text { Increased survival, reduced liver and gut pathology, and } \\
\text { serum level of TNF } \alpha \text {. }\end{array}$ \\
\hline \multirow[t]{2}{*}{ Jang et al. (59) } & $\begin{array}{l}\text { NSG, TBI } 2 \text { Gy, } 1 \times 10^{6} \\
\text { hPBMCs IV }\end{array}$ & $\begin{array}{l}5 \times 10^{5} \text { CB-MSCs IV, day } 0 \text { or days } 0,7 \\
\text { and } 14\end{array}$ & No significant increase in survival. \\
\hline & & $5 \times 10^{5}$ CB-MSCs IV, days 0,3 and 6 & $\begin{array}{l}\text { Increased survival, reduced tissue damage, lymphocyte } \\
\text { infiltration, and GVHD clinical scores. }\end{array}$ \\
\hline \multirow[t]{3}{*}{$\begin{array}{l}\text { Girdlestone } \\
\text { et al. (55) }\end{array}$} & $\begin{array}{l}\text { BALB/c RAG2 }-/-(\gamma \mathrm{c})^{-/-} \\
\text {TBI } 4 \text { Gy, } 15 \times 10^{6} \\
\text { hPBMCs IV }\end{array}$ & $0.5 \times 10^{6}$ UC-MSCs IV, day 8 & No significant increase in survival. \\
\hline & & $2 \times 10^{6}$ UC-MSCs IV, day 8 & Trend toward a longer survival. \\
\hline & & $0.5 \times 10^{6}$ rapamycin-UC-MSCs IV, day 8 & $\begin{array}{l}\text { Increased survival, lower proportion of human cells in the } \\
\text { spleen. }\end{array}$ \\
\hline Kim et al. (60) & $\begin{array}{l}\text { NOD/SCID, TBI } 3.2 \text { Gy, } \\
20 \times 10^{6} \text { hPBMCs IV }\end{array}$ & $\begin{array}{l}1 \times 10^{6} \text { BM-MSCs (normoxia or } 1 \% \mathrm{O}_{2} \text { ) IV, } \\
\text { days } 0 \text { and } 7 \text { or days } 0,3 \text {, and } 6\end{array}$ & $\begin{array}{l}\text { Increased survival, reduced GVHD symptoms (no difference } \\
\text { between normoxia and hypoxia). }\end{array}$ \\
\hline \multicolumn{4}{|l|}{ TREATMENT } \\
\hline Tisato et al. (57) & $\begin{array}{l}\text { NOD/SCID, TBI } 2.5 \text { Gy, } \\
20 \times 10^{6} \text { hPBMCs IV }\end{array}$ & $\begin{array}{l}3 \times 10^{6} \text { CB-MSCs IV } 4 \text { times every } 3 \text { days at } \\
\text { GVHD onset }\end{array}$ & No change in weight loss and human T-cell expansion. \\
\hline Jang et al. (59) & $\begin{array}{l}\text { NSG, TBI } 2 \text { Gy, } 1 \times 10^{6} \\
\text { hPBMCs IV }\end{array}$ & $\begin{array}{l}5 \times 10^{5} \text { CB-MSCs IV, either day } 18 \text {, days } 18 \text {, } \\
21 \text { and } 24 \text {, or days } 18,25 \text {, and } 32\end{array}$ & $\begin{array}{l}\text { Increased survival, reduced weight loss, clinical scores, tissue } \\
\text { damage, and lymphocyte infiltration. }\end{array}$ \\
\hline $\begin{array}{l}\text { Amarnath } \\
\text { et al. (61) }\end{array}$ & $\begin{array}{l}\text { NSG, } 5 \times 10^{6} \text { Th } 1 \text { cells }+ \\
3 \times 10^{6} \text { monocytes IV }\end{array}$ & $2 \times 10^{6}$ BM-MSCs IV, days 22, 26, and 30 & $\begin{array}{l}\text { Increased survival, reversal of cutaneous GVHD and weight } \\
\text { loss, decreased proportion of human Th1 cells in the spleen. }\end{array}$ \\
\hline Ma et al. (62) & $\begin{array}{l}\text { NOD/SCID, CY + aASGM1 } \\
\text { Ab IP, } 10 \times 10^{6} \text { hPBMCs IV }\end{array}$ & $1 \times 10^{6}$ placenta-derived MSCs IV, day 11 & $\begin{array}{l}\text { Increased survival, reduced weight loss, reduced lung and } \\
\text { intestinal damage, increased serum level of TGF } \beta \text {, decreased } \\
\text { serum level of IL-6 and IL-17, reduced Th17/Tr1 ratio in } \\
\text { spleen and liver. }\end{array}$ \\
\hline
\end{tabular}

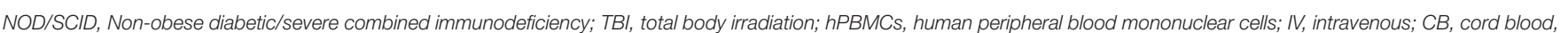

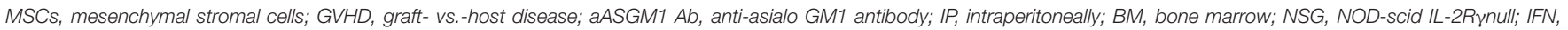
interferon; g BW, gram of body weight UC, umbilical cord; Th1, Thelper 1; CY, Cyclophosphamide; Tr1, type 1 regulatory T cells (CD4+IL10+).

most efficiently induced Tregs and inhibit Th17 cells, while BM-MSCs induced higher proportions of $\mathrm{CD} 4^{+} \mathrm{IL} 10^{+}$cells. AT-MSCs induced both Tregs and $\mathrm{CD}^{+}{ }^{+} \mathrm{IL} 10^{+}$cells. We also observed a lower proportion of Th1 cells on day 28 in mice treated with UC-MSC in the 3rd cohort. Direct comparisons of the effects of MSCs of different origins on T-lymphocyte subsets are scarce (29). UC-MSCs were shown to induce Tregs more potently than BM-MSCs in vitro (69) or to the same extent in a rat model of sepsis (70). MSCs could also induce other types of regulatory $\mathrm{T}$ cells although conflicting data have been reported concerning the mechanisms involved (71) and the comparison between BM- and UC-MSCs $(67,72)$. Regarding Th17 cells, most studies demonstrated a suppressive effect of MSCs, but no comparison between BM-, UC- and AT-MSC potency has been reported. We did not observe a reduction in the proportion of $\mathrm{CD}^{+}$cells secreting IFN $\gamma$ in co-culture with MSCs in this experimental setting. This is consistent with prior observations by De Witte et al. who observed a decrease in the percentage of $\mathrm{CD}^{+} \mathrm{T}$ cells containing intracellular IFN $\gamma$ only at higher MSC/PBMC ratios (73), while Ribeiro et al. observed an upregulation of T-bet mRNA with BM-, UC- and AT-MSCs (74). 
Finally, we also demonstrated that BM-MSCs are far less procoagulant than UC- and AT-MSCs. However, despite a similar activation of coagulation in vitro, UC-MSCs resulted in only 1 death after infusion in mice, while 4 mice infused with ATMSCs died, suggesting that other factors than their potential to activate coagulation may be involved. Cell size and expression of adhesion receptors are key factors in pulmonary cell trapping, so the higher size of AT-MSCs might be at least partially responsible. Similar results have been observed with murine AT-MSCs (46) and human decidual stromal cells (DSCs) (47). In humans, while BM-MSCs have demonstrated their safety, there are a few cases of thrombotic events following infusions of AT-MSCs (75). MSCs activate coagulation through tissue factor expression, which is expressed at higher levels on AT- and placenta-derived MSCs (45). Heparin infusion was shown to prevent this effect in a porcine model of acute myocardial infarction (76). BM-MSCs have also been used to treat hemorrhages in a few patients (gastro-intestinal bleeding, hemorrhagic cystitis) (77). The higher procoagulant effects of UC- and AT-MSCs might be of interest in these settings.

There are limitations in our study. First, we did not include placenta-derived decidua stromal cells (DSCs) among the sources of stromal cells we compared. Indeed, recent studies in humans have suggested that these cells could be more potent than BM-MSCs to treat acute GVHD (78). Secondly, it has been recently demonstrated that monocytes are important for induction of Tregs by MSCs in vitro (79). Moreover, in a murine model of GVHD, apoptosis of MSCs induced by cytolytic cells (NK and $\mathrm{CD}^{+}$cells) and phagocytosis of apoptotic MSCs by macrophages were necessary to MSCinduced immunosuppression (80). Given that human monocytes / macrophages do not engraft in NSG mice, it is possible that the humanized NSG mouse model is not the most suitable model to study the impact of MSCs on GVHD. However, one could argue that NSG mice have nevertheless functional autologous macrophage and dendritic cells that are able to modulate the activity of infused human PBMCs (52). Other potential limitations of this study are the fact that the timing of the first MSC administration might have been too late, when irreversible immunological mechanisms were already in place, or that the GVHD induced by injection of HLA-A2-negative PBMC in NSG-HLA-A2 mice (combining xeno- and allo- reactions) is perhaps too strong to be counterbalanced by immune regulatory mechanisms. However, one could also argue that the dose of PBMC infused in our study $\left(1-1.5 \times 10^{6} \mathrm{PBMC} /\right.$ mice $)$ was rather in the lower range of what has been used to induce GVHD in NSG or NSG-HLA-A2 mice. Finally, in order to take into consideration genetic variability, we elected to include different PBMC and MSC donors for each experiment to increase the robustness of our results. In order to tackle the variability issue, we performed multivariate Cox models that confirmed a significant impact of the PBMC donors (as previously reported $(36,37)$, no impact of mouse gender and weight, as well as no impact of MSC infusion on survival (Supplementary Table 1).

In summary, our data show that BM-, AT-, and UC-MSCs have differential effects on immune cells. UC-MSCs seem to promote a more "resting" phenotype in lymphocytes, with a potent down-regulation of HLA-DR, a higher induction of Tregs, and a decreased proportion of pro-inflammatory cells. On the other hand, BM-MSCs promote higher IL10 expression by T lymphocytes, but also more inflammatory features, especially when primed in inflammatory conditions. In vivo, both BM- and UC-MSCs failed to significantly delay GVHD mortality. Other types of MSCs derived from fetal membranes seem promising for GVHD therapy, and it would be interesting to compare them to BM- and UC-MSCs in preclinical studies. Also, gene modification of MSCs (for example in order to force secretion of regulatory cytokines such as IL-10) might increase their ability to protect against GVHD (81). Finally, the procoagulant effects of UC-MSCs and AT-MSCs should be taken into consideration in further clinical studies.

\section{DATA AVAILABILITY}

All datasets generated for this study are included in the manuscript and/or the Supplementary Files.

\section{AUTHOR CONTRIBUTIONS}

CG, CR, MH, LD, and SD performed the experiments. CG and FB analyzed and interpreted the data. LS made the statistical analyses. SV isolated and cultured the AT-MSCs and CL and AB the BM-MSCs. LB, GE, SS, and YB helped in data interpretation. $\mathrm{CG}$ and $\mathrm{FB}$ designed the research and wrote the article. All authors edited the manuscript and approved its final version.

\section{FUNDING}

This study was supported by funds from: the National Fund for Scientific Research (FNRS) (Grant No. T.0132.14 and T.0069.15), the Leon Fredericq fund and Anti-Cancer Center at the University of Liège (ULiege), and the Belgian Foundation against Cancer (FBC, Grants FBC C/2014/204). CG, LD, GE, and $\mathrm{CR}$ are (or have been) Télévie $\mathrm{PhD}$ students, $\mathrm{FB}$ is senior research associate of the FNRS.

\section{ACKNOWLEDGMENTS}

We would like to specially thank Sandra Ormenese, Raafat Stephan, and Jean-Jacques Goval from the Imaging and Flow Cytometry Platform of the GIGA for their help with flow cytometry and Bio-Plex analyses, Pierre Peters and Christelle Lecut for their help with ROTEM analyzes, the Laboratory of Cellular and Gene Therapy in the CHU of Liège who provided the BM-MSCs and the Endocrine Cell Therapy unit of the Center of Tissular and Cellular Therapy, directed by Denis Dufrane (Cliniques Universitaires Saint-Luc, Brussels, Belgium), who provided the AT-MSCs.

\section{SUPPLEMENTARY MATERIAL}

The Supplementary Material for this article can be found online at: https://www.frontiersin.org/articles/10.3389/fimmu. 2019.00619/full\#supplementary-material 


\section{REFERENCES}

1. Baron F, Storb R. Allogeneic hematopoietic cell transplantation as treatment for hematological malignancies: a review. Springer Semin Immunopathol. (2004) 26:71-94. doi: 10.1007/s00281-004-0165-3

2. Dickinson AM, Norden J, Li S, Hromadnikova I, Schmid C, Schmetzer H, et al. Graft- vs.-leukemia effect following hematopoietic stem cell transplantation for leukemia. Front Immunol. (2017) 8:496. doi: 10.3389/fimmu.2017.00496

3. Bleakley M, Riddell SR. Molecules and mechanisms of the graft- vs.-leukaemia effect. Nat Rev Cancer. (2004) 4:371-80. doi: 10.1038/nrc1365

4. Blazar BR, Murphy WJ, Abedi M. Advances in graft-vs.-host disease biology and therapy. Nat Rev Immunol. (2012) 12:443-58. doi: 10.1038/nri3212

5. Ghimire S, Weber D, Mavin E, Wang XN, Dickinson AM, Holler E. Pathophysiology of GvHD and other HSCT-related major complications. Front Immunol. (2017) 8:79. doi: 10.3389/fimmu.2017.00079

6. Zeiser R, Socie G, Blazar BR. Pathogenesis of acute graft- vs.-host disease: from intestinal microbiota alterations to donor T cell activation. Br J Haematol. (2016) 175:191-207. doi: 10.1111/bjh.14295

7. Baron F, Labopin M, Niederwieser D, Vigouroux S, Cornelissen JJ, Malm C, et al. Impact of graft- vs.-host disease after reduced-intensity conditioning allogeneic stem cell transplantation for acute myeloid leukemia: a report from the Acute Leukemia Working Party of the European group for blood and marrow transplantation. Leukemia. (2012) 26:2462-8. doi: 10.1038/leu.2012.135

8. Baron F, Ruggeri A, Beohou E, Labopin M, Mohty M, Sanz J, et al. Occurrence of graft- vs.-host disease increases mortality after umbilical cord blood transplantation for acute myeloid leukemia: a report from Eurocord and the ALWP of the EBMT. J Intern Med. (2018) 283:178-89. doi: 10.1111/joim.12696

9. Zeiser R, Blazar BR. Acute graft- vs.-host disease - biologic process, prevention, and therapy. N Engl J Med. (2017) 377:2167-79. doi: 10.1056/NEJMra1609337

10. Socie G, Vigouroux S, Yakoub-Agha I, Bay JO, Furst S, Bilger K, et al. A phase 3 randomized trial comparing inolimomab vs. usual care in steroid-resistant acute GVHD. Blood. (2017) 129:643-9. doi: 10.1182/blood-2016-09-738625

11. Dominici M, Le BK, Mueller I, Slaper-Cortenbach I, Marini F, Krause D, et al. Minimal criteria for defining multipotent mesenchymal stromal cells. The international society for cellular therapy position statement. Cytotherapy. (2006) 8:315-7. doi: 10.1080/14653240600855905

12. Le Blanc K, Mougiakakos D. Multipotent mesenchymal stromal cells and the innate immune system. Nat Rev Immunol. (2012) 12:383-96. doi: $10.1038 /$ nri3209

13. Reis M, Ogonek J, Qesari M, Borges NM, Nicholson L, Preussner $\mathrm{L}$, et al. Recent developments in cellular immunotherapy for HSCTassociated complications. Front Immunol. (2016) 7:500. doi: 10.3389/fimmu. 2016.00500

14. Davies LC, Heldring N, Kadri N, Le Blanc K. Mesenchymal stromal cell secretion of programmed death-1 ligands regulates $\mathrm{T}$ cell mediated immunosuppression. Stem Cells. (2017) 35:766-76. doi: 10.1002/stem.2509

15. Baron F, Storb R. Mesenchymal stromal cells: a new tool against graft- vs.-host disease? Biol Blood Marrow Transplant. (2012) 18:822-40. doi: 10.1016/j.bbmt.2011.09.003

16. Zhang L, Yu J, Wei W. Advance in targeted immunotherapy for graft- vs.-host disease. Front Immunol. (2018) 9:1087. doi: 10.3389/fimmu.2018.01087

17. Blazar BR, MacDonald KPA, Hill GR. Immune regulatory cell infusion for graft- vs.-host disease prevention and therapy. Blood. (2018) 131:2651-60. doi: 10.1182/blood-2017-11-785865

18. Ball LM, Bernardo ME, Roelofs H, Lankester A, Cometa A, Egeler RM, et al. Cotransplantation of ex vivo expanded mesenchymal stem cells accelerates lymphocyte recovery and may reduce the risk of graft failure in haploidentical hematopoietic stem-cell transplantation. Blood. (2007) 110:2764-7. doi: 10.1182/blood-2007-04-087056

19. Ning H, Yang F, Jiang M, Hu L, Feng K, Zhang J, et al. The correlation between cotransplantation of mesenchymal stem cells and higher recurrence rate in hematologic malignancy patients: outcome of a pilot clinical study. Leukemia. (2008) 22:593-9. doi: 10.1038/sj.leu.2405090

20. Baron F, Lechanteur C, Willems E, Bruck F, Baudoux E, Seidel L, et al. Cotransplantation of mesenchymal stem cells might prevent death from graft- vs.-host disease (GVHD) without abrogating graft- vs.tumor effects after HLA-mismatched allogeneic transplantation following nonmyeloablative conditioning. Biol Blood Marrow Transpl. (2010) 16:83847. doi: 10.1016/j.bbmt.2010.01.011

21. Kallekleiv M, Larun L, Bruserud O, Hatfield KJ. Co-transplantation of multipotent mesenchymal stromal cells in allogeneic hematopoietic stem cell transplantation: a systematic review and meta-analysis. Cytotherapy. (2016) 18:172-85. doi: 10.1016/j.jcyt.2015.11.010

22. Le Blanc K, Frassoni F, Ball L, Locatelli F, Roelofs H, Lewis I, et al. Mesenchymal stem cells for treatment of steroid-resistant, severe, acute graft- vs.-host disease: a phase II study. Lancet. (2008) 371:1579-86. doi: 10.1016/S0140-6736(08)60690-X

23. Chen X, Wang C, Yin J, Xu J, Wei J, Zhang Y. Efficacy of mesenchymal stem cell therapy for steroid-refractory acute graft- vs.-host disease following allogeneic hematopoietic stem cell transplantation: a systematic review and meta-analysis. PloS ONE. (2015) 10:e0136991. doi: 10.1371/journal.pone.0136991

24. Servais S, Baron F, Lechanteur C, Seidel L, Selleslag D, Maertens $\mathrm{J}$, et al. Infusion of bone marrow derived multipotent mesenchymal stromal cells for the treatment of steroid-refractory acute graft- vs.-host disease: a multicenter prospective study. Oncotarget. (2018) 9:20590-604. doi: 10.18632/oncotarget.25020

25. Hashmi S, Ahmed M, Murad MH, Litzow MR, Adams RH, Ball LM, et al. Survival after mesenchymal stromal cell therapy in steroid-refractory acute graft- vs.-host disease: systematic review and meta-analysis. Lancet Haematol. (2016) 3:e45-52. doi: 10.1016/S2352-3026(15)00224-0

26. Martin PJ, Uberti JP, Soiffer RJ, Klingemann H, Waller EK, Daly AS, et al. Prochymal improves response rates in patients with steroid-refractory acute graft vs. host disease (SR-GVHD) involving the liver and gut: results of a randomized, placebo-controlled, multicenter phase III trial In GVHD. Biol Blood Marrow Transpl. (2010) 16 (Suppl. 2):S169-70. doi: 10.1016/j.bbmt.2009.12.057

27. Galipeau J, Sensebe L. Mesenchymal stromal cells: clinical challenges and therapeutic opportunities. Cell Stem Cell. (2018) 22:824-33. doi: 10.1016/j.stem.2018.05.004

28. Waterman RS, Tomchuck SL, Henkle SL, Betancourt AM. A new mesenchymal stem cell (MSC) paradigm: polarization into a proinflammatory MSC1 or an Immunosuppressive MSC2 phenotype. PLoS ONE. (2010) 5:e10088. doi: 10.1371/journal.pone.0010088

29. Mattar P, Bieback K. Comparing the immunomodulatory properties of bone marrow, adipose tissue, and birth-associated tissue mesenchymal stromal cells. Front Immunol. (2015) 6:560. doi: 10.3389/fimmu.2015.00560

30. Waldner M, Zhang W, James IB, Allbright K, Havis E, Bliley JM, et al. Characteristics and immunomodulating functions of adipose-derived and bone marrow-derived mesenchymal stem cells across defined human leukocyte antigen barriers. Front Immunol. (2018) 9:1642. doi: 10.3389/fimmu.2018.01642

31. Ehx G, Somja J, Warnatz HJ, Ritacco C, Hannon M, Delens L, et al. Xenogeneic graft- vs.-host disease in humanized NSG and NSG-HLA-A2/HHD mice. Front Immunol. (2018) 9:1943. doi: 10.3389/fimmu.2018.01943

32. Betts BC, Veerapathran A, Pidala J, Yang H, Horna P, Walton K, et al. Targeting aurora kinase A and JAK2 prevents GVHD while maintaining Treg and antitumor CTL function. Sci Transl Med. (2017) 9:eaai8269. doi: 10.1126/scitranslmed.aai8269

33. Lechanteur C, Briquet A, Giet O, Delloye O, Baudoux E, Beguin Y. Clinicalscale expansion of mesenchymal stromal cells: a large banking experience. $J$ Transl Med. (2016) 14:145. doi: 10.1186/s12967-016-0892-y

34. Veriter S, Andre W, Aouassar N, Poirel HA, Lafosse A, Docquier PL, et al. Human adipose-derived mesenchymal stem cells in cell therapy: safety and feasibility in different "hospital exemption" clinical applications. PloS ONE. (2015) 10:e0139566. doi: 10.1371/journal.pone.0139566

35. Shultz LD, Saito Y, Najima Y, Tanaka S, Ochi T, Tomizawa M, et al. Generation of functional human T-cell subsets with HLA-restricted immune responses in HLA class I expressing NOD/SCID/IL2r gamma(null) humanized mice. Proc Natl Acad Sci USA. (2010) 107:13022-7. doi: 10.1073/pnas.1000475107

36. Hannon M, Lechanteur C, Lucas S, Somja J, Seidel L, Belle L, et al. Infusion of clinical-grade enriched regulatory $\mathrm{T}$ cells delays experimental xenogeneic graft- vs.-host disease. Transfusion. (2014) 54:353-63. doi: 10.1111/trf.12279 
37. Delens L, Ehx G, Somja J, Vrancken L, Belle L, Seidel L, et al. In vitro Th17-polarized human $\mathrm{CD} 4(+) \mathrm{T}$ cells exacerbate xenogeneic graft- vs.-host disease. Biol Blood Marrow Transpl. (2018) 25:204-15. doi: 10.1016/j.bbmt.2018.10.007

38. Ryan JM, Barry F, Murphy JM, Mahon BP. Interferon-gamma does not break, but promotes the immunosuppressive capacity of adult human mesenchymal stem cells. Clin Exp Immunol. (2007) 149:353-63. doi: 10.1111/j.1365-2249.2007.03422.x

39. Polchert D, Sobinsky J, Douglas G, Kidd M, Moadsiri A, Reina E, et al. IFN-gamma activation of mesenchymal stem cells for treatment and prevention of graft vs. host disease. Eur J Immunol. (2008) 38:1745-55. doi: 10.1002/eji.200738129

40. Luk F, Carreras-Planella L, Korevaar SS, de Witte SFH, Borras FE, Betjes $\mathrm{MGH}$, et al. Inflammatory conditions dictate the effect of mesenchymal stem or stromal cells on B cell function. Front Immunol. (2017) 8:1042. doi: 10.3389/fimmu.2017.01042

41. Yan L, Zheng D, Xu RH. Critical role of tumor necrosis factor signaling in mesenchymal stem cell-based therapy for autoimmune and inflammatory diseases. Front Immunol. (2018) 9:1658. doi: 10.3389/fimmu.2018.01658

42. Boland L, Burand AJ, Brown AJ, Boyt D, Lira VA, Ankrum JA. IFNgamma and TNF-alpha pre-licensing protects mesenchymal stromal cells from the pro-inflammatory effects of palmitate. Mol Ther. (2018) 26:860-73. doi: 10.1016/j.ymthe.2017.12.013

43. Reddy M, Eirikis E, Davis C, Davis HM, Prabhakar U. Comparative analysis of lymphocyte activation marker expression and cytokine secretion profile in stimulated human peripheral blood mononuclear cell cultures: an in vitro model to monitor cellular immune function. J Immunol Methods. (2004) 293:127-42. doi: 10.1016/j.jim.2004.07.006

44. Bruck F, Belle L, Lechanteur C, De LL, Hannon M, Dubois S, et al. Impact of bone marrow-derived mesenchymal stromal cells on experimental xenogeneic graft- vs.-host disease. Cytotherapy. (2013) 15:267-79. doi: 10.1016/j.jcyt.2012.09.003

45. Moll G, Ignatowicz L, Catar R, Luecht C, Sadeghi B, Hamad O, et al. Different procoagulant activity of therapeutic mesenchymal stromal cells derived from bone marrow and placental decidua. Stem Cells Dev. (2015) 24:2269-79. doi: $10.1089 / \mathrm{scd} .2015 .0120$

46. Tatsumi K, Ohashi K, Matsubara Y, Kohori A, Ohno T, Kakidachi H, et al. Tissue factor triggers procoagulation in transplanted mesenchymal stem cells leading to thromboembolism. Biochem Biophys Res Commun. (2013) 431:2039. doi: 10.1016/j.bbrc.2012.12.134

47. Sadeghi B, Heshmati Y, Khoein B, Kaipe H, Uzunel M, Walfridsson J, et al. Xeno-immunosuppressive properties of human decidual stromal cells in mouse models of alloreactivity in vitro and in vivo. Cytotherapy. (2015) 17:1732-45. doi: 10.1016/j.jcyt.2015.09.001

48. Le Blanc K, Rasmusson I, Sundberg B, Gotherstrom C, Hassan M, Uzunel $\mathrm{M}$, et al. Treatment of severe acute graft- vs.-host disease with third party haploidentical mesenchymal stem cells. Lancet. (2004) 363:1439-41. doi: 10.1016/S0140-6736(04)16104-7

49. King MA, Covassin L, Brehm MA, Racki W, Pearson T, Leif J, et al. Human peripheral blood leucocyte non-obese diabetic-severe combined immunodeficiency interleukin-2 receptor gamma chain gene mouse model of xenogeneic graft- vs.-host-like disease and the role of host major histocompatibility complex. Clin Exp Immunol. (2009) 157:104-18. doi: 10.1111/j.1365-2249.2009.03933.x

50. Kanakry CG, Ganguly S, Zahurak M, Bolanos-Meade J, Thoburn C, Perkins $\mathrm{B}$, et al. Aldehyde dehydrogenase expression drives human regulatory $\mathrm{T}$ cell resistance to posttransplantation cyclophosphamide. Sci Transl Med. (2013) 5:211 ra157. doi: 10.1126/scitranslmed.3006960

51. Cuende J, Lienart S, Dedobbeleer O, van der Woning B, De Boeck G, Stockis J, et al. Monoclonal antibodies against GARP/TGF-betal complexes inhibit the immunosuppressive activity of human regulatory T cells in vivo. Sci Transl Med. (2015) 7:284ra56. doi: 10.1126/scitranslmed.aaa1983

52. Coman T, Rossignol J, D'Aveni M, Fabiani B, Dussiot M, Rignault R, et al. Human CD4- invariant NKT lymphocytes regulate graft vs. host disease. Oncoimmunology. (2018) 7:e1470735. doi: 10.1080/2162402X.2018.1470735

53. Ehx G, Fransolet G, de Leval L, D'Hondt S, Lucas S, Hannon M, et al. Azacytidine prevents experimental xenogeneic graft- vs.-host disease without abrogating graft- vs.-leukemia effects. Oncoimmunology. (2017) 6:e1314425. doi: 10.1080/2162402X.2017.1314425

54. Joo SY, Cho KA, Jung YJ, Kim HS, Park SY, Choi YB, et al. Mesenchymal stromal cells inhibit graft- vs.-host disease of mice in a dose-dependent manner. Cytotherapy. (2010) 12:361-70. doi: 10.3109/14653240903502712

55. Girdlestone J, Pido-Lopez J, Srivastava S, Chai J, Leaver N, Galleu A, et al. Enhancement of the immunoregulatory potency of mesenchymal stromal cells by treatment with immunosuppressive drugs. Cytotherapy. (2015) 17:118899. doi: 10.1016/j.jcyt.2015.05.009

56. Tobin LM, Healy ME, English K, Mahon BP. Human mesenchymal stem cells suppress donor CD4(+) $\mathrm{T}$ cell proliferation and reduce pathology in a humanized mouse model of acute graft- vs.-host disease. Clin Exp Immunol. (2013) 172:333-48. doi: 10.1111/cei.12056

57. Tisato V, Naresh K, Girdlestone J, Navarrete C, Dazzi F. Mesenchymal stem cells of cord blood origin are effective at preventing but not treating graftvs.-host disease. Leukemia. (2007) 21:1992-9. doi: 10.1038/sj.leu.2404847

58. Gregoire-Gauthier J, Selleri S, Fontaine F, Dieng MM, Patey N, Despars G, et al. Therapeutic efficacy of cord blood-derived mesenchymal stromal cells for the prevention of acute graft- vs.-host disease in a xenogenic mouse model. Stem Cells Dev. (2012) 21:1616-26. doi: 10.1089/scd.2011.0413

59. Jang YK, Kim M, Lee YH, Oh W, Yang YS, Choi SJ. Optimization of the therapeutic efficacy of human umbilical cord blood-mesenchymal stromal cells in an NSG mouse xenograft model of graft- vs.-host disease. Cytotherapy. (2014) 16:298-308. doi: 10.1016/j.jcyt.2013.10.012

60. Kim DS, Lee MW, Ko YJ, Park HJ, Park YJ, Kim DI, et al. Application of human mesenchymal stem cells cultured in different oxygen concentrations for treatment of graft- vs.-host disease in mice. Biomed Res. (2016) 37:311-7. doi: 10.2220/biomedres.37.311

61. Amarnath S, Foley JE, Farthing DE, Gress RE, Laurence A, Eckhaus MA, et al. Bone marrow-derived mesenchymal stromal cells harness purinergenic signaling to tolerize human Th1 cells in vivo. Stem Cells. (2015) 33:1200-12. doi: 10.1002/stem.1934

62. Ma Y, Wang Z, Zhang A, Xu F, Zhao N, Xue J, et al. Human placenta-derived mesenchymal stem cells ameliorate GVHD by modulating Th17/Tr1 balance via expression of PD-L2. Life Sci. (2018) 214:98-105. doi: 10.1016/j.lfs.2018.10.061

63. Pires AO, Mendes-Pinheiro B, Teixeira FG, Anjo SI, Ribeiro-Samy S, Gomes $\mathrm{ED}$, et al. Unveiling the differences of secretome of human bone marrow mesenchymal stem cells, adipose tissue-derived stem cells, and human umbilical cord perivascular cells: a proteomic analysis. Stem Cells Dev. (2016) 25:1073-83. doi: 10.1089/scd.2016.0048

64. Ito R, Katano I, Kawai K, Yagoto M, Takahashi T, Ka Y, et al. A novel xenogeneic graft- vs.-host disease model for investigating the pathological role of human CD4(+) or CD8(+) T cells using immunodeficient NOG mice. Am J Transpl. (2017) 17:1216-28. doi: 10.1111/ajt.14116

65. Li X, Bai J, Ji X, Li R, Xuan Y, Wang Y. Comprehensive characterization of four different populations of human mesenchymal stem cells as regards their immune properties, proliferation and differentiation. Int J Mol Med. (2014) 34:695-704. doi: 10.3892/ijmm.2014.1821

66. Fazzina R, Iudicone P, Fioravanti D, Bonanno G, Totta P, Zizzari IG, et al. Potency testing of mesenchymal stromal cell growth expanded in human platelet lysate from different human tissues.* Stem Cell Res Ther. (2016) 7:122. doi: 10.1186/s13287-016-0383-3

67. Prasanna SJ, Gopalakrishnan D, Shankar SR, Vasandan AB. Pro-inflammatory cytokines, IFNgamma and TNFalpha, influence immune properties of human bone marrow and Wharton jelly mesenchymal stem cells differentially. PloS ONE. (2010) 5:e9016. doi: 10.1371/journal.pone.0009016

68. Jitschin R, Mougiakakos D, von BL, Volkl S, Moll G, Ringden O, et al. Alterations in the cellular immune compartment of patients treated with third-party mesenchymal stromal cells following allogeneic hematopoietic stem-cell transplantation. Stem Cells. (2013) 31:1715-25. doi: $10.1002 /$ stem. 1386

69. Barcia RN, Santos JM, Filipe M, Teixeira M, Martins JP, Almeida J, et al. What makes umbilical cord tissue-derived mesenchymal stromal cells superior immunomodulators when compared to bone marrow derived mesenchymal stromal cells? Stem Cells Int. (2015) 2015:583984. doi: 10.1155/2015/ 583984 
70. Chao YH, Wu HP, Wu KH, Tsai YG, Peng CT, Lin KC, et al. An increase in $\mathrm{CD} 3+\mathrm{CD} 4+\mathrm{CD} 25+$ regulatory $\mathrm{T}$ cells after administration of umbilical cordderived mesenchymal stem cells during sepsis. PloS ONE. (2014) 9:e110338. doi: 10.1371/journal.pone.0110338

71. Patel SR, Copland IB, Garcia MA, Metz R, Galipeau J. Human mesenchymal stromal cells suppress T-cell proliferation independent of heme oxygenase-1. Cytotherapy. (2015) 17:382-91. doi: 10.1016/j.jcyt.2014.11.010

72. Karlsson H, Erkers T, Nava S, Ruhm S, Westgren M, Ringden O. Stromal cells from term fetal membrane are highly suppressive in allogeneic settings in vitro. Clin Exp Immunol. (2012) 167:543-55. doi: 10.1111/j.1365-2249.2011.04540.x

73. de Witte SFH, Merino AM, Franquesa M, Strini T, van Zoggel JAA, Korevaar SS, et al. Cytokine treatment optimises the immunotherapeutic effects of umbilical cord-derived MSC for* treatment of inflammatory liver disease. Stem Cell Res Ther. (2017) 8:140. doi: 10.1186/s13287-017-0590-6

74. Ribeiro A, Laranjeira P, Mendes S, Velada I, Leite C, Andrade P, et al. Mesenchymal stem cells from umbilical cord matrix, adipose tissue and bone marrow exhibit different capability to suppress peripheral blood B, natural killer and T cells. Stem Cell Res Ther. (2013) 4:125. doi: 10.1186/scrt336

75. Jung JW, Kwon M, Choi JC, Shin JW, Park IW, Choi BW, et al. Familial occurrence of pulmonary embolism after intravenous, adipose tissue-derived stem cell therapy. Yonsei Med J. (2013) 54:1293-6. doi: 10.3349/ymj.2013.54.5.1293

76. Gleeson BM, Martin K, Ali MT, Kumar AH, Pillai MG, Kumar SP, et al. Bone marrow-derived mesenchymal stem cells have innate procoagulant activity and cause microvascular obstruction following intracoronary delivery: amelioration by antithrombin therapy. Stem Cells. (2015) 33:2726-37. doi: 10.1002/stem.2050

77. Ringden O, Uzunel M, Sundberg B, Lonnies L, Nava S, Gustafsson J, et al. Tissue repair using allogeneic mesenchymal stem cells for hemorrhagic cystitis, pneumomediastinum and perforated colon. Leukemia. (2007) 21:2271-6. doi: 10.1038/sj.leu.2404833
78. Ringden O, Baygan A, Remberger M, Gustafsson B, Winiarski J, Khoein $\mathrm{B}$, et al. Placenta-derived decidua stromal cells for treatment of severe acute graft- vs.-host disease. Stem Cells Transl Med. (2018) 7:325-31. doi: 10.1002/sctm.17-0167

79. Melief SM, Schrama E, Brugman MH, Tiemessen MM, Hoogduijn MJ, Fibbe WE, et al. Multipotent stromal cells induce human regulatory $\mathrm{T}$ cells through a novel pathway involving skewing of monocytes toward anti-inflammatory macrophages. Stem Cells. (2013) 31:1980-91. doi: 10.1002/stem.1432

80. Galleu A, Riffo-Vasquez Y, Trento C, Lomas C, Dolcetti L, Cheung TS, et al. Apoptosis in mesenchymal stromal cells induces in vivo recipient-mediated immunomodulation. Sci Transl Med. (2017) 9:eaam7828. doi: 10.1126/scitranslmed.aam7828

81. Min CK, Kim BG, Park G, Cho B, Oh IH. IL-10-transduced bone marrow mesenchymal stem cells can attenuate the severity of acute graft- vs.-host disease after experimental allogeneic stem cell transplantation. Bone Marrow Transpl. (2007) 39:637-45. doi: 10.1038/sj.bmt.1705644

Conflict of Interest Statement: FB has received travel grants from Celgene, Abbvie, Novartis, and Sanofi.

The remaining authors declare that the research was conducted in the absence of any commercial or financial relationships that could be construed as a potential conflict of interest.

Copyright () 2019 Grégoire, Ritacco, Hannon, Seidel, Delens, Belle, Dubois, Vériter, Lechanteur, Briquet, Servais, Ehx, Beguin and Baron. This is an open-access article distributed under the terms of the Creative Commons Attribution License (CC BY). The use, distribution or reproduction in other forums is permitted, provided the original author(s) and the copyright owner(s) are credited and that the original publication in this journal is cited, in accordance with accepted academic practice. No use, distribution or reproduction is permitted which does not comply with these terms. 